\title{
Ergonomics
}

\section{Collecting evidence from distributed sources to evaluate railway suicide and trespass prevention measures}

Brendan Ryan, Veli-Pekka Kallberg, Helena Rådbo, Grigore M. Havârneanu, Anne Silla, Karoline Lukaschek, Jean-Marie Burkhardt, Jean-Luc Bruyelle, ElMiloudi El-Koursi, Eric Beurskens \& Maria Hedqvist

To cite this article: Brendan Ryan, Veli-Pekka Kallberg, Helena Rådbo, Grigore M. Havârneanu, Anne Silla, Karoline Lukaschek, Jean-Marie Burkhardt, Jean-Luc Bruyelle, El-Miloudi ElKoursi, Eric Beurskens \& Maria Hedqvist (2018): Collecting evidence from distributed sources to evaluate railway suicide and trespass prevention measures, Ergonomics, DOI: 10.1080/00140139.2018.1485970

To link to this article: https://doi.org/10.1080/00140139.2018.1485970

Accepted author version posted online: 08 Jun 2018.

Submit your article to this journal $₫$

Q View related articles $\asymp$

View Crossmark data 


\section{Collecting evidence from distributed sources to evaluate railway suicide and trespass prevention measures}

Brendan Ryan*, Veli-Pekka Kallberg ${ }^{\mathrm{b}}$, Helena Rådbo ${ }^{\mathrm{c}}$, Grigore M. Havârneanu ${ }^{\mathrm{d}}$, Anne Silla ${ }^{\mathrm{b}}$, Karoline Lukaschek ${ }^{\mathrm{e}}$, Jean-Marie Burkhardt ${ }^{\mathrm{f}}$, Jean-Luc Bruyelle ${ }^{\mathrm{g}}$, El-Miloudi El-Koursi ${ }^{\mathrm{h}}$, Eric

Beurskens ${ }^{\mathrm{i}}$, Maria Hedqvist ${ }^{\mathrm{c}}$

${ }^{a}$ University of Nottingham, Faculty of Engineering, University Park, Nottingham NG7 2RD, United Kingdom.

${ }^{\mathrm{b}}$ VTT, Technical Research Centre of Finland Ltd, P.O. Box 1000, 02044 VTT, Finland.

${ }^{c}$ Trafikverket, 78189 Borlänge, Sweden.

d International Union of Railways (UIC), Security division, 16 rue Jean Rey, F-75015 Paris, France.

${ }^{\mathrm{e}}$ Institute of General Practice and Family Medicine, University Hospital of Ludwig-Maximilians-University Munich, Pettenkoferstr. 10, D-80336 Munich, Germany and Helmholtz Zentrum München, German Research Centre for Environmental Health, Institute of Epidemiology. Ingolstädter Landstr.1, 85764 Neuherberg, Germany.

${ }^{\mathrm{f}}$ IFSTTAR-LPC, 25, allée des Marronniers, Satory, 78000 Versailles, France.

g University of Lille 3, France.

${ }^{\text {h }}$ IFSTTAR-ESTAS, 20, rue Elisée Reclus, BP 70317, 59666 Villeneuve d'Ascq Cedex, France.

${ }^{i}$ Prorail, ProRail, De Inktpot, Moreelsepark 3, Utrecht, The Netherlands.

* Corresponding author brendan.ryan@nottingham.ac.uk 


\title{
Collecting evidence from distributed sources to evaluate railway suicide and trespass prevention measures
}

\begin{abstract}
It can be difficult to select from available safety preventative measures, especially where there is limited evidence of effectiveness in different contexts. This paper describes application of a method to identify and evaluate wide-ranging preventative measures for rail suicide and trespass fatalities. Evidence from literature and industry sources was collated and reviewed in a two stage process to achieve consensus among experts on the likely effects of the measures and factors influencing their implementation. Multiple evaluation criteria were used to examine the measures from different perspectives. Fencing, awareness campaigns and different types of organisational initiatives were recommended for further testing. This is the first time evidence has been collected internationally across such a range of preventative measures. Commentary is provided on using this type of approach to select safety measures from a pool of prevention options, including how reframing the scope of the exercise could identify alternative options for prevention.

Practitioner summary. The findings give insight to how different measures work in different ways and how industry can consider this in strategic initiatives. The method could be used in future studies with different frames of reference (e.g. different timescales, level of ambition and safety context e.g. railway crossings or highway fatalities).
\end{abstract}

Keywords: Rail fatalities; Suicide; Trespass; Prevention; Evaluation; Experts and consensus methods 


\section{Introduction}

Close to 3000 railway suicides occur on European mainline railways each year. This represents about $72 \%$ of all railway fatalities and together with trespass related deaths, $89 \%$ of all fatalities occurring within the European railway system in 2012-2014 (European Union Agency for Railways 2016).

The railway industry is working to minimise the loss of life (e.g. see targets to reduce fatalities in Government Offices of Sweden 2016) and associated trauma to staff. This has needed a paradigm change and innovative thinking, taking account of individual, organisational and societal factors that can impact on these fatalities. There are many possible solutions. Some of the published work (e.g. Havârneanu et al. 2015) identifies and explains different types of preventative measures. However, the greatest challenge is in knowing what works and how, in the range of circumstances that are typical in international railways. The published evidence is not sufficient to provide the necessary guidance for the industry. This is not unusual within the published literature on evaluation studies in other areas of safety and ergonomics (e.g. Guastello 1993; Volinn 1999; Neumann et al. 1999; discussed in greater detail below).

The RESTRAIL project (http://www.restrail.eu) brought together seventeen major railway organisations, research institutes and universities from twelve countries, providing opportunities for gathering knowledge and wide-scale consultation on prevention measures. Whilst detailed testing of preferred preventative measures in different European contexts was a longer term goal, a preliminary phase of work was needed to identify the most appropriate measures that could be considered across Europe for prevention. This paper describes the application of a method that combines best practice from evaluation and consensus methodology to identify and evaluate wide ranging measures for prevention of railway suicides and trespassing incidents. Recommendations are made for preventative measures that should be examined in more detailed field studies.

\section{Background}

\subsection{Existing evaluation studies for rail suicide and trespass}

Many different preventative measures have been implemented internationally, with the intention of reducing the frequencies of fatalities. Review publications (e.g. Botha et al. 2014; Gabree et al. 2014) contain references to different prevention strategies, such as fencing, redesign of lighting, media guidelines, education and warnings to people, use of patrols or prohibitive signs. Whilst these contain explanatory details of these prevention measures there are limited published details on the potential effectiveness of the measures.

Havârneanu et al. (2015) carried out a systematic review of evidence in the literature in parallel with this current evaluation study. Nineteen measures were identified (shown later in Table 6), ordered by frequency of citations across twenty two publications that considered the effectiveness of 
suicide and trespass measures. Whilst the evidence is building, there are still limited numbers of good studies of safety interventions in the railway environment.

There are many reasons why it is difficult to study the effectiveness of these types of rail safety interventions. Firstly, it can be hard to transfer findings from one country to another (Elvik 2012), because of specific cultural and sociological phenomena. Havârneanu et al's (2015) review revealed that most of the existing evaluation results come from single studies from one country or limited contexts. Only physical barriers (Law et al. 2009, Beautrais at al. 2009, Lobb et al. 2001 and Silla and Luoma 2011) and media guidelines (Hegerl et al. 2013 and Etzersdorfer and Sonneck 1998) had sufficient evidence from multiple studies in a variety of cultural contexts. Extraneous factors (e.g. socio-economic factors), can influence the numbers of suicides in a location (Too et al, 2014, 2015), though it has been difficult to demonstrate such effects in recent studies (Uittenbogaard and Ceccato 2015). There are also important differences in how prevention measures may function in suicide and trespass events. Media guidelines, for example, are implemented specifically for suicide, to ensure responsible reporting about incidents and to avoid copycat effects (Hegerl et al. 2012). Similarly, trained staff at stations (Isaac et al. 2009) can help people who contemplate suicide. Warning signs (Lobb et al. 2001) are more appropriate for prevention of trespass. Barriers (e.g. Law et al. 2009) can protect against suicide and trespass. However, there are situations where a safety measure can reduce incidents in one situation but increase incidents in another. For example, a verbal warning of the approach of a fast, non-stopping train could reduce the numbers of accidental events at a station, but increase awareness of an approaching train for suicidal people. It is therefore important to understand the different motivations of people and how these might influence the likely success of preventative measures. Useful process models have also been developed to describe how preventative measures can be applied at different points in the period before an event (Rådbo et al. 2008; Burkhardt et al. 2014). These models classify preventative measures by five different mechanisms: measures that focus on influencing the perceived attractiveness and availability of rail traffic as a means of suicide, measures influencing access to tracks, early warning measures to enable a fast response to threats, measures to persuade people to leave a place of danger and measures to minimise the consequences of collision.

\subsection{Previous safety evaluation studies}

Many existing evaluation studies consider one or a small number of safety measures in a given context. Neumann et al. (2010) have suggested that evaluation studies need to move beyond the traditional experimental approaches (e.g. randomised control trials) that are highly regarded in the scientific literature. Review of guidance from the safety literature (Shannon et al. 1999; Baril-Gingras et al. 2006), including those advocating realistic evaluation approaches (Nilsen 2007; Pawson et al. 2005; Pederson et al. 2012) emphasise the need for the following components in evaluation studies: clear statements of study objectives; focus on the concept or theory behind the safety measures; 
explicit descriptions of the safety measure, the context in which it is implemented and the participants; and specification of a variety of potential outcome indicators. In the current study, decision makers need to be able to select from a range of possible safety measures. It is necessary to distinguish strong research from other less well-designed work (Elvik 2008, 2012), in the process of identifying the interventions with the greatest potential for future application. However, evaluation can be difficult where there is a paucity of detail on both the implementation and outcomes from the interventions within the published evidence (Guastello 1993; Volinn 1999). An example of the type of study that is needed is described in Siegrist (2010), assessing national road safety programme measures, to prioritise those with the potential to save the greatest numbers of lives. Siegrist's method highlights the importance of clearly identifying the types of accidents that are impacted by a measure, also describing a process of calculating maximum and average reductions in fatalities. This considers the target number of incidents that could be influenced by the preventative measure, the proportion of the incidents that the measure can be applied to, the proportion that can be prevented with implementation and the extent of implementation of the measure. Siegrist is aware of limitations in available data relating to interventions and recommends being explicit about the data sources and estimates that are used, as well as presenting forecasts for decision makers as a range.

Elvik and colleagues (Elvik 2012; SUPREME 2007) embarked on a similar task, aiming to select the best road safety measures from options across Europe. The SUPREME method used country based experts to gather information from European stakeholders. Safety measures were classified, selected and ranked, in order to identify those that could bring about a sustained reduction in fatalities. Their method was built around the use of eight selection criteria (shown later in Table 1).

\subsection{Applying appropriate methods to evaluate wide ranging preventative measures}

Where there is limited scientific evidence or where the evidence is contradictory, experts are often consulted (Fink et al. 1984; Morgan and Mansfield 2014; Piccoli 2003). It is necessary to consider how consensus is achieved where members of an expert group are interpreting evidence from disparate sources. Several consensus methods are available, including nominal group, Delphi and consensus panel methods (Fink et al. 1984; Keeney et al. 2011; Murphy et al. 1998; Waggoner et al. 2016). None of these methods in their pure forms were appropriate for the types of ratings, validation and discussions that were needed to gather the additional evidence for the current study. However, the underlying principles and typical steps in consensus studies (Fink et al. 1984; Murphy et al. 1998) were considered. These included ensuring clarity and relevance of the task or question to be addressed, appropriate selection of participants, choosing and preparing the scientific evidence, structuring the interaction between participants, and having effective methods for collecting and synthesising individual judgements. 
In conclusion, it was clear that the evidence on rail suicide and trespass prevention was scarce and difficult to access, with relevant knowledge and practical experience widely distributed across individuals, organisations and countries. Furthermore, there was no existing shared framework or preestablished criteria for evaluation of suicide and trespass prevention measures. This indicated that both the content and the evaluation method should be elaborated and agreed on between expert participants. The constituent parts for this method are available, drawing upon the following: the existing methodology for evaluation of safety interventions (Shannon et al. 1998; Baril-Gingras et al. 2006), best practice for reaching consensus (Fink et al. 1984; Murphy et al. 1998; Waggoner et al. 2016) and the practically based evaluation criteria that have been used in road safety studies (Siegrist 2010; SUPREME 2007).

\section{Method}

The main features of the evaluation method are illustrated in Figure 1 and explained below.

[Figure 1 about here]

\subsection{Clarifying the tasks and questions to be addressed}

The study had a number of purposes (i) identifying and collating evidence on known preventative measures and (ii) identifying the most promising measures for prevention that are candidates for testing in future field trials. These were achieved using qualitative and quantitative data from literature and expert input in a two stage consultation process.

\subsection{Selecting appropriate participants and allocating roles}

All participants were members of the RESTRAIL consortium or nominated by consortium members, working in positions where they had specialist knowledge of research or practice in the prevention of rail suicide and trespass. This included industry staff who have the power to implement solutions and can provide essential contributions to this type of expert group (Fink et al. 1984).

Two researchers worked on developing the process and refining evaluation criteria for use in the study. A core group of ten (Figure 1 for details) took part in a series of tasks to collect details of all known preventative measures and collate evidence about the implementation and effectiveness of these measures, section 3.3). Twenty two participants (the core group, plus an additional twelve participants) participated in the second stage of the evaluation, reviewing and discussing evidence and ratings on the implementation and effectiveness of each type of measure (Section 3.4). The members of the core group analysed the data, after the larger group consultation (Section 3.5).

\subsection{Preparing appropriate scientific evidence}

This was carried out by the core group and involved two main activities, as explained below. 


\subsubsection{Identification and preliminary classification of known preventative measures}

Working within the RESTRAIL consortium offered good opportunities to collect details of known preventative measures across Europe. This included search for content in literature and industry documentation, as well as collecting additional knowledge from industry staff. A questionnaire was sent to all project partners, asking about which preventative measures have been implemented, whether the effectiveness of these measures had been evaluated and details of new measures that could be used (Silla et al. 2012). Responses were collated and screened by the core group, using a card sorting exercise to remove duplications. A list of 90 preventative measures was produced and these were grouped into 38 "types of measures". A type of measure included several measures that share common contexts or effect mechanisms, for example grouping together different fencing interventions. A full list of these types is provided later in Section 4.

\subsubsection{Collation of evidence on types of preventative measures}

A form was created to collate practical and empirical evidence from a number of different perspectives about the implementation and effectiveness of each type of preventative measure. The structure of this form was inspired by the content considered by Siegrist (2010) (e.g. target number of incidents, proportion of events that can be prevented) and the evaluation criteria from Elvik and colleagues (SUPREME 2007). Elvik's evaluation criteria were supplemented by incorporating elements from RAMSHEC (Reliability, Availability, Maintainability, Safety, Health, Environment and Costs, Jovanovic and Zoeteman 2010) for a better fit to this railway context. Fourteen evaluation criteria were produced, as listed in Table 1.

[Table 1 about here]

Evidence was collected from existing publications or other industry sources in a series of iterative steps by members of the core group. Each core group member was assigned a subset of the preventative measures (from Section 3.3.1) and they added evidence or commentary to a form for each of the measures. Completed forms were then returned to the coordinating researcher and any questions arising from the exercise were discussed in a group teleconference. The forms were then re-allocated to another member of the core group for review and addition of supplementary evidence. There was a minimum of four rounds of review (up to a maximum of six rounds) for the content of forms for each type of measure. This was the first stage in building consensus on the evidence amongst members of the core group.

The set of evaluation criteria was also used to produce four different types of ratings, as detailed below.

\subsubsection{Safety effect score}


The annual reduction in fatalities following implementation of the different measures was estimated using criterion 4 (Table 1), giving a preliminary indication of the effectiveness of measures. The effects were estimated at a European Union (EU) level by a researcher from the core group, taking the annual numbers of railway suicides and trespassing accidents in EU countries as a starting point (2,854 suicides and 782 trespassing fatalities, using data from the European Railway Agency Database of Interoperability and Safety - ERADIS database, and the International Union of Railways - UIC safety database of incidents, Silla et al. 2012,). This estimate considered the following factors:

- the size of the target group - this could be influenced by the location of the incidents, the context in which the measure is implemented (such as lighting conditions in daytime or night time) or the type of target groups of people;

- the expected level of implementation - this was the assumed proportion of target incidents it was considered possible and realistic to cover by the measure, within a reasonable time period;

- the expected percentage reduction in target incidents - this was estimated and later discussed and adjusted by consensus of the wider group of experts (section 3.4), including consideration of the numbers of incidents occurring in different contexts.

A spreadsheet (Excel) based calculator tool was used to calculate and record these estimates.

\subsubsection{Total Qualitative Score}

Ratings were produced for each of the types of preventative measures on nine of the remaining evaluation criteria (criteria 5 to 13). To produce these, one of the core group members (from an infrastructure management organisation) completed a scoring exercise, assigning values of $2,1,0$, for each of the criteria ( 2 where no problems were foreseen in implementation of the measure with respect to the criteria in question; 1 where minor problems were anticipated; 0 where major problems were anticipated). Explanations of the rationale for the ratings were recorded in a document (e.g. why a particular measure may be rated lower on criteria such as cost or the impact on railway operations). As an example, the criteria for the durability of the effect for the measure of Fences was scored 2 for suicide and 1 for trespass, because it was felt that trespassers would be more willing to climb fences than people who were attempting suicide. The ratings were recorded in a matrix for each type of measure, as assessed against the nine evaluation criteria. 


\subsubsection{Implementation score}

As part of the analysis of these ratings (from 3.3.2.2), the matrix of scores was reviewed to identify any "zero scores" on criteria for each of the measures. A zero rating on one criterion or more means that there are likely to be major problems in implementing the measure. Zero scores were highlighted in the matrix.

\subsubsection{Survey Score}

A small survey of project partners and their contacts was carried out in nine countries across Europe (UK, Spain, The Netherlands, Sweden, Israel, Turkey, France, Germany, Switzerland), to collect ratings of their preferences for different types of preventative measures. Industry stakeholders in each of these countries received a list of the thirty eight types of measures and ranked their top five preventative measures from the list. Responses were used to produce the Survey Score, providing an initial indication of the numbers of countries in which each type of measure was thought to be effective.

\subsection{Reviewing and achieving consensus on evidence, estimates and ratings for the different types of measures}

The second stage of achieving consensus on the evidence involved a meeting with the wider group of experts (22 people), to validate the available evidence and to collect new perspectives on implementation of the measures (e.g. knowledge from the industry or other details of evaluation studies or data).

\subsubsection{Preparing for the expert meeting}

The approach to managing discussions and developing consensus was considered prior to the meeting. Firstly, important roles were allocated. The facilitator took on roles of planning and controlling the sequence of tasks for the meeting, so that consensus on evidence for each preventative measure could be achieved in the time available. The Secretary, like the HAZOP secretary (Kletz 1986; Kirwan and Ainsworth 1992), took on the role of summarising the content of discussions and recording the rationale for decisions. One participant planned to present the preliminary estimates and collect the supporting rationale for the likely effects of the presentative measures (Section 3.3.2.1). Another presented the simple ratings and supporting rationale for ratings on factors affecting implementation of each preventative measure (Section 3.3.2.2 and 3.3.2.3). A judge or adjudicator was identified, if an agreement could not be reached.

Rules for agreement on the evidence were established. Opinions of people from different backgrounds were valued (e.g. the opinion of a rail infrastructure manager could give a different insight to someone from a research background). A majority decision was not necessarily essential, reflecting that there can be strong national perspectives in this study with worldwide application and compelling arguments could overcome an initial majority view. It was not necessary to demonstrate 
conclusive evidence that a measure would be effective, as promising measures could be trialled in different locations in later phases of the programme of work. In practice, this was a transparent process with a clear structure and there were no major disagreements that could not be resolved at the meeting.

A shorter set of reference material was created by summarising content from the multiple rounds of collating and reviewing the evidence by the core group. This reference material contained a clear description of each of the preventative measures, relevant descriptive content for each of the evaluation criteria, preliminary ratings on factors influencing implementation and estimates for the size of the problem, explained in section 3.3.2. The reference material was given to the group prior to the meeting.

\subsubsection{Procedures during the expert group meeting}

This meeting was carried out over one and a half days. The participants reviewed the content of the condensed version of the evidence, to validate the main conclusions from the collation of evidence. The four types of scores (Section 3.3.2) were used in discussion of the evidence and these were projected onto a screen so that they were visible to all participants during discussions for each type of measure. Displaying these meant that they could be adjusted with agreement of all participants.

To emphasise the uncertainty of the estimates for the Safety Effect Score (Section 3.3.2.1, i.e. the calculated potential reduction in the numbers of EU level fatalities), lower and upper values of the estimated effect were defined by consensus. Adjustments were also made for the Total Qualitative Score (sum of scores across a range of criteria, section 3.3.2.2). It was agreed at the meeting that a weighting of two should be assigned to the ratings for four of the criteria, so that greater emphasis was given to these over others. This weighting gave preferences to identifying measures that are likely to be durable, have a favourable cost-benefit ratio, have a low impact on railway operations and have the potential to transfer to other countries. Agreed scores were recorded in a table to enable comparisons across the types of measures.

\subsection{Analysing, synthesising and interpreting data on preventative measures, to provide recommendations for testing}

Judgements on the future use of the preventative measures were clarified in analyses after the expert meeting, using a combination of the four sources of data.

The primary goal of the evaluation was to choose RECOMMENDED and PROMISING measures from among those that were evaluated. In order to become RECOMMENDED the measure had to: exceed the threshold value (see later in Section 4) in all four data types: Safety Effect Score, Total Qualitative Score, Implementation Score and Survey Score.

The measures that did not qualify for the RECOMMENDED category were assigned to the PROMISING category if they exceed the threshold value in three out of four of the above mentioned 
data types, or exceed the threshold in two of the data types and perform well in comparison with other preventative measures with respect to the remaining data types.

\section{Results}

The evaluation results are summarised in Table 2.

[Table 2 about here]

Threshold values were identified for each type of data. These threshold values indicated the score or rating, above which a measure was assumed to score highly in comparison to others in the evaluation exercise.

\subsection{Safety effect score}

The estimated effect (i.e. estimated reductions in the numbers of fatalities across Europe) on the annual number of fatalities varied from 0 to 128 for measures targeted to prevent suicides and from 0 to 44 for measures against trespassing. This calculation used estimates of the likely percentage reduction in fatalities. As an example, an estimate of 0 to $5 \%$ reduction in fatalities was assumed for mass media campaigns, in comparison with $50-80 \%$ reduction for fencing at stations. This implies a greater success rate for fencing, but the calculation also considered that fencing would be likely to be applied at a smaller number of locations, in comparison with the potential reach of the media campaigns. Therefore, the final estimated reductions of suicide related fatalities were ranges of 21 to 207 and 74 to 118 for mass media campaigns and fencing at stations, respectively (Table 2).

In order to pass the threshold value for Safety Effect score, it was agreed by the expert group that the estimated annual reduction of fatalities should be over ten. Twenty three measures for the prevention of suicides and ten for the prevention of trespass passed the threshold value (marked "1" in the respective column of Table 2).

\subsection{Total qualitative score}

The results for Total Qualitative Score are shown also in Table 2. Ratings on each of the nine criteria for this score are presented in Table 3. The Total Qualitative Scores varied from 9 to 25 (with a maximum possible score of 26). A Total Qualitative Score of 21 was selected as the threshold value. Seventeen measures for the prevention of suicides and fourteen measures against trespass passed the threshold value.

[Table 3 about here] 
The table can be inspected to identify low scores on various criteria. For example, there were low scores on many criteria for the two train design solutions to reduce the impact of collisions. The airbag solution was rated lower than the redesign of the front of the trains.

\subsection{Implementation score}

Potential implementation problems are indicated by the Implementation Score (i.e. zero scores in Table 3). The threshold value was that none of the nine criteria were rated as zero. Twenty two measures dedicated to the prevention of suicides and nineteen measures against trespass passed the threshold value for Implementation score. Inspection of "zero ratings" for the train design solutions shows that there were serious concerns around cost-benefit and technological issues with those solutions.

\subsection{Survey score}

Measures that were recommended by at least three of the railway professionals from seven countries were labelled as the strongest measures on this data type. This represented the upper quartile of the types of measures for suicide prevention and the top $40 \%$ of the measures for trespass prevention. Ten measures for the prevention of suicides and ten measures for the prevention of trespass passed this threshold criterion.

\subsection{Combining the results from the four scores}

Having regard to these thresholds for the scores on the four data types, sixteen measures were labelled as RECOMMENDED or PROMISING for the prevention of suicides, as indicated in Table 2. For the prevention of trespassing, ten measures were labelled as RECOMMENDED or PROMISING. Seven measures were labelled as RECOMMENDED or PROMISING for the prevention of both suicide and trespass. The results have been compared with evidence from the literature (also shown in Table 4) and are discussed in more detail in section 5 below.

[Table 4 about here]

\subsection{Descriptive comments from the discussion at the expert group workshop}

The contents of discussions of the rationale for ratings and estimates were recorded in a text format. Table 5 includes examples of a selection of comments, covering issues that could affect the implementation and likely success of the preventative measures. New measures were also identified during these discussions and further details of the implementation of these measures were considered. Occasionally, participants acknowledged problems in applying parts of the evaluation method. 
[Table 5 about here]

\subsection{Commentary on the findings from the evaluation exercise}

Nineteen of the 38 types of measures were either recommended or promising for the prevention of suicide or trespass (Table 4). There has generally been agreement between the findings from the evaluation process and the available literature (some of which have been published after this evaluation exercise) on the different types of measures (Table 4). The results from further classification of the measures are presented in Tables 6 and 7, to help with understanding of features of the preventative measures.

Table 6 examines how the preventative measures can be grouped according to similar types of measures (e.g. awareness / education, physical measures to restrict access, see also Table 4). The table shows the relative preferences for measures in these groupings and any differences in how these were evaluated in the literature based study by Havârneanu et al. (2015). Campaigns or provision of information in educational / awareness type initiatives were the most common measures that were selected, followed by organisational initiatives, physical measures, environmental design and surveillance. Of the nineteen types of measures that were not found to be recommended or promising, more than half of these involved surveillance, environmental design or organisational initiatives (Table 6). The less favoured measures were linked to train design, support for drivers, slowing down traffic or attempting to dissuade selection of the railway for suicide.

The classification from Rådbo et al. (2008) has been used to explore how the selected and less favoured preventative measures will exert their effects in practice, as shown in Table 7. The preventative measures are likely to work in different ways, often employing several of the underlying mechanisms of effect. Even where there is a clear main effect (e.g. fencing can inhibit access to the railway), a well-fenced station might also reduce the attractiveness of a station as a place of suicide or enable an early warning if someone is in a place that they should not be. Influencing the attractiveness of the railway as a place for railway suicide was the most common mechanism of effect for the selected measures.

[Table 6 and 7 about here]

\section{Discussion}

\subsection{Findings from this evaluation}

This evaluation study has brought together evidence on a wide range of practical prevention measures and provided a forum to explore the factors and circumstances that can impact on the implementation and success of these safety interventions. The evaluation process has been successful in its aim of discriminating between the different measures, identifying a shorter list of those that are recommended or promising for prevention of rail suicide and trespass (Tables 4,6). There are several 
ways in which the preventative measures can be classified. However, a workable set of types of measures was identified and grouping the measures was a valuable part of a first stage assessment that produced the preferred prevention strategies. Classifying the measures by their underlying mechanism of effect (Rådbo et al. 2008) demonstrates how the preferred measures work in different and often multiple ways. These are plausible mechanisms, but there is little information from existing field studies to clarify precisely how these work. The classification in this study enables researchers and industry staff to think about what they are trying to achieve and how they are doing this through application of different types of measures. It is worth questioning whether the right complement of measures is used and whether it is really understood how measures that are implemented are working, either alone or in combination.

It is interesting to see the relative preferences arising for awareness / educational approaches, which commonly aim to influence the attractiveness of the railway for suicide. Organisational initiatives such as risk assessment or fencing to restrict access to the railway were also selected (Table $6,7)$. There is currently limited compelling published evidence (Table 4) on the effectiveness of measures such as campaigns or risk assessment in the rail context, though there is strong support for the use of fencing (e.g. Cox et al. 2013; Law et al. 2009).

Lower overall ratings have been produced for several of the types of measures: various surveillance approaches that might provide early warning of risk; the design and reconfiguration of the railway environment; interventions to redesign trains or the infrastructure to reduce the impact of collisions; and attempts to support the driver through technology or training to reduce the likelihood of an event. These may be viable options for prevention, offering longer term benefits, but currently need more development. For example, many surveillance technologies are being developed (see the review in Ryan 2018). More extensive studies might be needed to explore solutions related to environmental design, such as novel lighting installations or better station layouts. These would not have been possible in the timeframe of a project such as RESTRAIL and therefore did not perform well in the current assessment exercise.

Gatekeeper training is another interesting absence from the measures that have been favoured in this evaluation. This measure incorporates aspects of surveillance and applies strategies to encourage trained staff to approach someone to prevent an incident. It receives support in the literature (Lukaschek et al. 2013; Cross et al. 2010; Isaac et al. 2009) and is being used at present in the industry (e.g. Great Britain, RSSB 2013).

Whilst collecting evidence from the expert group, there have been very few examples of preventative measures that were new or previously unknown. This is perhaps not surprising, as the experts were reporting on what is generally known and used within the industry. In the future, new prevention measures may emerge by considering how the more promising types of preventative measures could be adapted to respond to the known challenges for prevention of railway suicide and 
trespass. It is likely that expert judgement in this study has been influenced by the framing of the problem. Outcomes have been conservative with good reason in this study, which was identifying preventative measures that could be tested in a short period of time. More ambition and novelty in the selection of measures could be achieved by applying the method of evaluation using different terms of reference and instructions to participants about the likely timescales and risks for implementation of the preventative measures.

\subsection{Application of the method of evaluation in real world contexts}

There are many different ways to evaluate preventative measures for suicide and trespass on the railway. This can be achieved by looking at individual measures (e.g. in field studies such as Ueda et al. 2015), but the large numbers of options collected in the opening parts of this study indicated that this would not be feasible. The current research has applied a method to investigate and compare many potential safety interventions, covering both the implementation of the measure and likely outcomes of the measure (Nilsen 2007; Pawson et al. 2005; Pederson et al. 2012). There are many common features of methods that are used for the prevention of deliberate or accidental events. Similar evaluation processes were used to study suicide and trespass interventions, whilst bearing in mind differences in the context and behaviours of those involved.

This type of evaluation of multiple preventative measures for railway fatalities has not been attempted previously and there have been no similar studies to collate the necessary evidence. The evaluation process and mutual learning involving both research and field experts in this study has therefore created the evidence where it has been lacking, because of the absence or the quality of studies (Elvik 2012) in this rail context. This has included review of studies on similar interventions, such as fencing at bridges (Law et al. 2014), to determine the way in which a measure works and its likely effect in a set of anticipated circumstances. The evaluation method that has been applied is not new, but combines known methods in a novel way to investigate a special issue that poses challenging problems for rail administrations. An extensive body of evidence has been produced about these preventative measures, providing a useful resource and guidance for the industry (http://www.restrail.eu/toolbox/; Wisniewski and Havârneanu 2016).

There are some limitations in the evaluation method that has been applied. Firstly, there is a lack of evidence on which to base ratings, estimates and conclusions during the review process. This was of course the reason for convening the groups of experts. It is recognised that expert opinion can be classified as lower than several others on a hierarchy of evidence (Foth et al. 2016) and that in the use of consensus methods there is no right answer, just consensus on the available evidence (Fink et al. 1984; Keeney et al. 2011). Evidence from consensus of experts was needed to fill gaps in knowledge in the current study and led to a pragmatic conclusion (Volinn 1999).

It is accepted that there is imprecision in the estimates and ratings, and there could be bias according to what is familiar to the expert participants in their own organisations, fields of research or countries. There are potential weaknesses in use of any one of the data types on their own. For 
example, the stakeholder survey was small, only a very simple rating system was used with each of the criteria, and various approximations and assumptions are needed in determining estimates of effect. To counteract this, results from the various data types are synthesised to produce the final recommendations. Combining the types of data allowed comparison of the different preventative measures across multiple attributes and corroboration of the evidence. This gave greater confidence in the selection of the best measures for more detailed testing in future work. The results from this exercise also established the reasoning for why these are preferred (e.g. because of no problems with implementation, assessed across a range of criteria). It is possible to see through inspection of the ratings where preventative measures are likely to be strong or weak and the levels of improvement in safety that could be achieved.

Another limitation is the potential for bias in the interaction between group members, with a tendency towards agreement or undue influence of some members of the group. This could have been countered by collecting separate ratings (e.g. using a Delphi technique). However, this study was about learning as well as consensus and a method was needed that encouraged discussion between the experts that were available. Steps were taken during the facilitation of the group consultations to ensure full visibility of the findings and encourage contributions. This included requests for new evidence or alternative viewpoints, recording the rationale used in decision making and adjusting estimates for effect size based on knowledge of different local conditions.

Finally, this evaluation study, as is the case in previous research activities (van der FeltzCornelis et al. 2011; Gabree et al. 2014), has largely considered the evaluation of single measures. This has been necessary as a first step in understanding the mechanisms of prevention. Testimony from rail organisations taking part has suggested that it is important to consider the application of many of the preventative measures in combination, because there may be synergy between different interventions as they counteract different risk factors on multiple levels (Guo and Harstall 2004). However, knowledge of how to combine different measures in an effective suicide or trespass prevention strategy is lacking (Mann et al. 2005). More in-depth evaluation of a collection of measures, in specific contexts (e.g. at stations, crossings or other locations), will need to be considered in field tests.

\section{Conclusions}

There is currently limited evidence on what types of safety prevention measures for rail suicide and trespass are effective (i.e. what works and in what circumstances). A method has been applied to collect new data to evaluate safety measures to prevent rail suicide and trespass fatalities. This has been based on existing best practice for evaluation and consensus studies, collecting and reviewing descriptive content, ratings on factors affecting implementation and estimates of the success of the preventative measures. This is the first time evidence has been collected by an international group of experts across such a large range of preventative measures. This type of evaluation can be 
applied at an early stage of a project to select from amongst a broad set of options. The study achieved its goal of identifying a shorter list of preventative measures that are appropriate for further testing in field studies. These included fencing, awareness campaigns, and organisational initiatives. The analysis gives insight to how different measures work in different ways and how the industry can consider this in strategic initiatives. The findings contribute to the evidence base in this area and can be used in setting the agenda for future exploratory studies for new interventions and especially combinations of interventions.

There were mixed findings about the value of some of the prevention measures, such as surveillance or design related interventions. Re-framing of the scope of the assessment might produce different results. Experience of use of the evaluation method indicates that it could feasibly be adapted and used in evaluating safety interventions in other contexts, such as to understand and select measures in more ambitious prevention programmes, with longer implementation periods and with other safety problems (e.g. collisions at railway crossings, suicide prevention measures on highways). More evidence is appearing within the literature on known and emerging interventions on rail suicide and trespass and the evaluation exercise can be reviewed and re-applied to take account of new knowledge.

[6565 words] 


\section{Acknowledgements}

The authors would like to thank all the partners of the RESTRAIL project and other colleagues, especially those who contributed to the expert workshop during this research.

\section{Funding}

This project has received funding from the European Union's Seventh Framework Programme for research, technological development and demonstration under grant agreement no. 285153. 


\section{References}

Andriessen, K., and K. Krysinska. 2011. "Railway suicide in Belgium 1998-2009”, Crisis: The Journal of Crisis Intervention and Suicide Prevention 26, 1-7.

Baril-Gingras, G., M. Bellemare, and J-P. Brun. 2006. "The contribution of qualitative analyses of occupational health and safety interventions: An example through a study of external advisory interventions" Safety Science 44, 851-874,

Baumert, J., K. Lukaschek, S. Kunrath, N. Erazo, and K-K. Ladwig. 2011. "Decrease in railway suicides between 1998 and 2006: evaluation of the German railway suicide prevention project" Journal of Epidemiology and Community Health 65(1), A91.

Beautrais, A. L., S.J. Gibb, D.M. Fergusson, L.J. Horwood, and G.L. Larkin. 2009. "Removing bridge barriers stimulates suicides: An unfortunate natural experiment" Australian \& New Zealand Journal of Psychiatry 43(6), 495-497.

Bhui, K., J. Chalangary, and E. Jones. 2013. Railway Suicides in the UK: Risk factors and prevention strategies. Cultural Consultation Service, NHS England, UK.

Botha, J. L., M.K. Neighbour, and S. Kaur. 2014. An Approach for Actions to Prevent Suicides on Commuter and Metro Rail Systems in the United States. MTI Report 12-33. San Jose, CA, USA: Mineta Transportation Institute - San Jose State University. http://transweb.sjsu.edu/PDFs/research/1129-2-preventing-suicide-on-US-rail-systems.pdf (retrieved 16 November, 2015)

Bureau of Transport and Regional Economics. 2002. Rail accident costs in Australia. Report No. 108, Canberra, Australia: Bureau of Transport and Regional Economics.

Burkhardt, J-M., H. Rådbo, A. Silla, and F. Paran. 2014. "A model of suicide and trespassing processes to support the analysis and decision related to preventing railway suicides and trespassing accidents at railways". A paper presented in Transport Research Arena 2014, Paris.

C.A.R.E. (Community, Analysis, Response and Evaluation) 2006. Trespassing on railway lines: A community problem-solving guide: Direction2006. Retrieved November 2012 from http:// www.operationlifesaver.ca/wp-content/uploads/2010/06/en_TrespGuide2003.pdf

Cox, G., C. Owens, J. Robinson, A. Nicholas, A. Lockley, M. Williamson, Y.T.D. Cheung, and J. Pirkis. 2013, "Interventions to reduce suicides at suicide hotspots: a systematic review" BMC Public Health 13, 214-225.

Cross, W., M.M. Matthieu, D. Lezine, and K.L. Knox. 2010. "Does a brief suicide prevention gatekeeper training program enhance observed skills?" Crisis 31, 149-159.

DaSilva, M., and A. Carroll. 2011. "Preliminary results of the trespass prevention research study in West Palm Beach, Florida". ASME Conference Proceedings, (54594), 571-577.

DaSilva, R., W. Baron, and A.A. Carroll. 2006. Highway rail-grade crossing safety research: Railroad infrastructure trespassing detection systems research in Pittsford, New York No. Form Approved OMB No. 0704-0188), available to the public through the National Technical Information Service, Springfield, Virginia 22161.: U.S. Department Railroad Infrastructure of Transportation.

du Roscoät, E., and F. Beck. 2013. "Efficient interventions on suicide prevention: A literature review" Revue d'Epidemiologie et de Sante Publique 61, 363-374.

Elvik, R. 2008. Making sense of road safety evaluation studies. Developing a quality scoring system, Institute of Transport Economics, Oslo, Sweden.

Elvik, R. 2012. "The range of replications technique for assessing validity of road safety evaluation studies" Accident Analysis and Prevention 45, 272- 280.

Erazo, N., J. Baumert, and K-H. Ladwig. 2004. "Regional and local clusters of railway suicides". Nervenarzt, 75(11), 1099-1106.

Erazo, N., J. Baumert, and K-H. Ladwig. 2005. "Factors associated with failed and completed railway suicides" Journal of Affective Disorders 88, 137-143.

Etzersdorfer, E., and G. Sonneck. 1998. "Preventing suicide by influencing mass-media reporting. The Viennese experience 1980-1996" Archives of Suicide Research 4(1), 67-74. 
European Union Agency for Railways, 2016. Railway safety performance in the European Union. European Union Agency for Railways, http://www.era.europa.eu/DocumentRegister/Pages/Railway-Safety-Performance.aspx (retrieved 10 January 2018).

Fink, A., J. Kosecoff, M. Chassin, and R.H. Brook. 1984. "Consensus methods: Characteristics and guidelines for use" American Journal of Public Health 74 (9), 979-983.

Foth, T., N. Efstathiou, B. Vanderspank-Wright, L-A. Ufholz, N. Dütthorn, M. Zimansky, and S. Humphrey-Murto. 2016. "The use of Delphi and Nominal Group Technique in nursing education: A review" International Journal of Nursing Studies 60 112-120.

Gabree, S.H., S. Chase, A. Doucette, and M. Martino. 2014. Countermeasures to mitigate intentional deaths on railroad rights-of-way: Lessons learned and next steps, US Department of Transportation, Federal Railroad Administration, Office of Research and Development, Washington, DC 20590, Final Report, November 2014.

George, B. F. 2007. Rail-trespasser fatalities developing demographic profiles. Cadle Creek Consulting.

Government Offices of Sweden, 2016. Renewed Commitment to Vision Zero. Intensified efforts for transport safety in Sweden, Government Offices of Sweden, Sweden. url. Accessed 12 November $2017 \mathrm{http}: / / \mathrm{www}$. government.se/articles/2016/10/renewed-commitment-to-vision-zero--intensified-efforts-for-transport-safety-in-sweden/

Guastello, S.J. 1993. "Do we really know how well our occupational accident prevention programs work?" Safety Science, 16, 445-463.

Guo, B, and C. Harstall. 2004. For which strategies of suicide prevention is there evidence of effectiveness? Copenhagen, WHO Regional office for Europe. Health Evidence Network report.

Havârneanu, G.M., J-M. Burkhardt, and F. Paran. 2015. "A systematic review of the literature on safety measures to prevent railway suicides and trespassing accidents". Accident Analysis \& Prevention, 81, 30-50.

Hegerl, U., N. Koburger, C. Rummel-Kluge, C., Gravert, M. Walden, and R. Mergl. 2013. "One followed by many? - Long-term effects of a celebrity suicide on the number of suicidal acts on the German railway net" Journal of Affective Disorders 146: 39-44.

Hepp, U., N. Stulz, J. Unger-Köppel, and V. Ajdacic-Gross. 2012. "Methods of suicide used by children and adolescents" European Child \& Adolescent Psychiatry 21(2), 67-73.

Holdaway, S., E. Evans, and S. Webb. 2012. Improving suicide prevention measures on the rail network in Great Britain. Literature Review. Rail Safety and Standards Board (T845), UK.

Horton, S. 2009. Success factors in the reduction of highway-rail grade crossing incidents. U.S. Department of Transportation, Research and Innovative Technology Administration, Volpe National Transportation Systems Center, Cambridge, MA USA.

Ichikawa, M., H. Inada, and M. Kumeji. 2014. "Reconsidering the effects of blue-light installation for prevention of railway suicides" Journal of Affective Disorders 152-154, 183-185.

Isaac, M., B. Elias, L.Y. Katz, S.L. Belik, F.P. Deane, M.W. Enns and J. Sareen. 2009, "Gatekeeper training as a preventative intervention for suicide: a systematic review" Can J Psychiatry 54:260 268.

Jovanovic, S., and A. Zoeteman. 2010. "Modern condition-based railway infrastructure asset management". A paper presented in First International Conference on Road and Rail Infrastructure. CETRA. http://www.mermecgroup.com/mermecincorso/images/File/papers/CETRA2010-paper-B.pdf (accessed May 28 2012).

Keeney, S., F. Hasson, and H. McKenna. 2011. The Delphi Technique in Nursing and Health Research. Blackwell Publishing Ltd., UK.

Kerkhof, A. 2003. "Railway suicide: Who is responsible? Editorial". Crisis: The Journal of Crisis Intervention and Suicide Prevention 24(2), 47-48.

Kirwan, B., and L.K. Ainsworth. 1992. A guide to task analysis. London: Taylor and Francis Ltd.

Kletz, T.,1986. HAZOP and HAZAN: notes on the identification and identification of hazards. Rugby, UK: Institution of Chemical Engineers.

Koburger, N., R. Mergl, A. Rummel-Kluge, A. Ibelshäuser, U. Meise, V. Postuvan, S. Roskar, A. Székely, M.D. Tóth, C. van der Feltz-Cornelis, and U. Hegerl. 2015. "Celebrity suicide on the railway network: Can one case trigger international effects?" Journal of Affective Disorders 185, $38-46$. 
Kunrath, S., J. Baumert, and K-H. Ladwig. 2011. "Increasing railway suicide acts after media coverage of a fatal railway accident? An ecological study of 747 suicidal acts" Journal of Epidemiology and Community Health 65(9), 825-828.

Ladwig, K-H., S. Kunrath, K. Lukaschek, and J. Baumert. 2012. "The railway suicide death of a famous German football player: Impact on the subsequent frequency of railway suicide acts in Germany" Journal of Affective Disorders 136(1-2), 194-198.

Ladwig, K. H., E. Ruf, J, Baumert, and N. Erazo. 2009. "Prevention of metropolitan and railway suicide". In D. Wasserman, \& C. Wasserman (Eds.), Oxford textbook of suicidology and suicide prevention. Oxford: Oxford University Press. pp. 589-594.

Law, C. K., and P.S.F. Yip. 2011. "An economic evaluation of setting up physical barriers in railway stations for preventing railway injury: Evidence from Hong Kong" Journal of Epidemiology and Community Health 65(10), 915-920.

Law, C.K., J. Sveticic, J., and D. De Leo. 2014. "Restricting access to a suicide hotspot does not shift the problem to another location. An experiment of two river bridges in Brisbane" Australia., Australian and New Zealand Journal of Public Health 38 (2), 134-138.

Law, C.K., P. Yip, W., Chan, K.W. Fu, P. Wong, P. and Y.W. Law. 2009. "Evaluating the effectiveness of barrier installation for preventing railway suicides in Hong Kong" Journal of Affective Disorder, 114(1-3), 254-262.

Lobb, B., N. Harré, and T. Nicola. 2003. "An evaluation of four types of railway pedestrian crossing safety intervention" Accident Analysis and Prevention 35(4), 487-494.

Lobb, B., N. Harré, and T. Suddendorf. 2001. "An evaluation of a suburban railway pedestrian crossing safety programme" Accident Analysis and Prevention 33(2), 157-165.

Lukaschek, K., K-H. Ladwig, B. Ryan, J. Plaza, and T. Kuljen, 2013. "New approach of soft measures for the prevention of railway suicide".

http://ovidentia.uic.org/index.php?tg=fileman\&idx=list\&id=329\&gr=Y\&path=RESTRAIL\%2FRE STRAIL+Deliverables\%2FRESTRAIL+Restricted+Deliverables.

Lukaschek, K., J. Baumert, M. Krawitz, N. Erazo, H. Förstl, and K-H Ladwig. 2014. "Determinants of completed railway suicides by psychiatric in-patients: case-control study". Br J Psychiatry. 205(5), 398-406.

Mann, J.J., A. Apter, J. Bertolote, A. Beautrais, D, Currier, A. Haas, U. Hegerl, H. Lonnqvist, K. Malone, A. Marusic, L. Mehlum, G. Patton, M. Phillips, W. Rutz, Z. Rihmer, A. Schmidtke, D. Shaffer, M., Silverman, Y, Takahashi, A Varnik, D. Wasserman, P., Yip, P. and H. Hendin. 2005. "Suicide prevention strategies: a systematic review" JAMA 294, 2064-2074.

Matsubayashi, T., Y. Sawada, and M. Ueda. 2013. "Does the installation of blue lights on train platforms prevent suicide? A before-and-after observational study from Japan" Journal of Affective Disorders 147(1-3), 385-388.

Mishara, B., 2007. "Railway and metro suicides - Understanding the problem and prevention potential" Crisis: The Journal of Crisis Intervention and Suicide Prevention 28, 36-43.

Mohanty, M.K., M.K. Panigrahi, S. Mohanty, S. and K.K. Patnaik. 2007. "Death due to traumatic railway injury" Medicine Science and the Law 47(2), 156-160.

Morgan, L.J., and N. J. Mansfield. 2014. "A survey of expert opinion on the effects of occupational exposures to trunk rotation and whole-body vibration" Ergonomics 57 (4), 563-574.

Murphy, M.K., N.A. Black, D.L. Lamping, C.M. McKee, C.F.B. Sanderson, J. Askham, and T. Marteau. 1998. "Consensus development methods and their use in clinical guideline development" Health Technology Assessment 2 (3), 1-89.

Neumann, W.P., J. Eklund, B. Hansson, and L. Lindbeck. 2010. "Effect assessment in work environment interventions: A methodological reflection" Ergonomics 53(1), 130-137.

Niederkrotenthaler, T. and G. Sonneck, G., 2007. "Assessing the impact of media guidelines for reporting on suicides in Austria: interrupted time series analysis" Australian and New Zealand Journal of Psychiatry 41: 419-428.

Niederkrotenthaler, T., G. Sonneck, K. Dervic, L.W. Nader, M. Voracek, N.D. Kapusta, E. Etzersdorfer, E. Mittendorfer-Rutz, and T. Dorner. 2012. "Predictors of suicide and suicide attempt in subway stations: a population-based ecological study" Journal of Urban Health 89: 339-353.

Nilsen, P. 2007. "The how and why of community based injury prevention. A conceptual and evaluation model" Safety Science 45, 501-521. 
Offler, N., K. Thompson, L. Hirsch, M. Thomas, and D. Dawson. 2009. A review of the literature on social non technical deterrents for vandalism in the rail industry No. RT 106. Brisbane: CRC for Rail Innovation.

Patterson, T. 2004. Analysis of trespasser accidents. Land Transport Safety Authority, New Zealand.

Pawson, T., T. Greenhalgh, G. Harvey, and K. Walshe. 2005. "Realist review - a new method of systematic review designed for complex policy interventions" J Health Serv Res Policy 10 Suppl 1, 21-34.

Pedersen, L.M., K.J. Nielsen, and P. Kines. 2012. "Realistic evaluation as a new way to design and evaluate occupational safety interventions" Safety Science 50, 48-54.

Pelletier, A., 1997. "Deaths among railroad trespassers. The role of alcohol in fatal injuries" Journal of American Medical Association 277(13), 1064-1066.

Piccoli, B. 2003. "A critical appraisal of current knowledge and future directions of ergophthalmology: consensus document of the ICOH Committee on 'Work and Vision"' Ergonomics 46(4), 348-406.

Pirkis, J., T.S. Too, M.J. Spittal, K. Krysinska, J. Robinson, and Y.T.D Cheung. 2015. "Interventions to reduce suicides at suicide hotspots: a systematic review and meta-analysis" The Lancet Psychiatry 2 (11), 994-1001.

Rådbo, H., L. Svedung, and R. Andersson. 2008. "Suicide prevention in a railway system: Application of a barrier approach" Safety Science 46, 729-737.

Reisch, T., and K. Michel. 2005. "Securing a suicide hot spot: Effects of a safety net at the Bern Muenster Terrace" Suicide and Life-Threatening Behavior 34(4), 460-467.

RESTRAIL, 2014. RESTRAIL toolbox. Output from the RESTRAIL project co-funded by the European Commission within the 7th Framework Programme. http://www.restrail.eu/toolbox/ (retrieved 27/10/2014)

Routley, V., C. Staines, N. Haworth, M. Symmons, and J. Ozanne-Smith. 2004. Rail-related suicides in Victoria, Analysis of databases and literature review. Monash University Accident Research Centre - Report \#215.

RSSB, 2002. Public Behaviour. Railway crime - industry perceptions. Railway Safety Research Programme. London UK.

RSSB, 2003. Trespass - transferable lessons from a review of safety campaigns. Desk Research Report, London UK.

RSSB, 2005. Trespass and access via the platform end. Final Report. Halcrow Group Limited in partnership with Human Engineering, London UK..

RSSB, 2011. Annual safety performance report 2010/2011. Rail Safety and Standards Board. London UK..

RSSB, 2012. Learning from Operational Experience Annual Report 2011/12. Rail Safety and Standards Board, London UK..

RSSB, 2013. Improving suicide prevention methods on the rail network in Great Britain. Annual Report 2013 (T845), London UK.

Ryan, B. 2018. "Developing a framework of behaviours before suicides at railway locations" Ergonomics 61 (5), 605-626.

Savage, I. 2007. "Trespassing on the railroad" Research in Transportation Economics 20, 199-224.

Schmidtke, A. and H. Häfner. 1988. "The Werther effect after television films: new evidence for an old hypothesis" Psychological Medicine 18(3): 665-76.

Shannon, H., L.S. Robson, and S.J. Guaselloc. 1999. "Methodological criteria for evaluating occupational safety intervention research" Safety Science 31, 161-179.

Siegrist, S. 2010. "Towards a method to forecast the effectiveness of national road safety programmes" Safety Science 48, 1106-1110.

Silla, A., and J. Luoma. 2011. "Effect of three countermeasures against the illegal crossing of railway tracks" Accident Analysis \& Prevention 43(3), 1089-1094.

Silla, A., V-P. Kallberg, L. Leden, S. Salenius , H. Rådbo, B. Ryan, S. Whalley, A. Tauler, L., Lorenzo, E. Prieto, K. Lukaschek, J-M Burkhardt, F. Paran, J.J. Plaza.2012. Data concerning railway suicides and trespassing accidents, Deliverable D1.1, RESTRAIL. 
SUPREME, 2007. Summary and publication of best practices in road safety in the Member States: Methodology.http://ec.europa.eu/transport/roadsafety_library/publications/supreme_a_methodolog y.pdf (retrieved 1/29/2014).

Thompson, K., N. Offler, L. Hirsch, D. Every, M.J.Thomas, and D. Dawson. 2012. "From broken windows to a renovated research agenda: A review of the literature on vandalism and graffiti in the rail industry" Transportation Research Part A: Policy and Practice 46(8), 1280-1290.

Too, L.S., A. Milner, L. Bugeja, and R. McClure. 2014. "The socio-environmental determinants of railway suicide: a systematic review" BMC Public Health 14:20. doi:10.1186/1471-2458-14-20

Too, L.S., M.J. Spittal, L. Bugeja, A. Milner, M. Stevenson, and R. McClure. 2015. "An investigation of neighborhood-level social, economic and physical factors for railway suicide in Victoria" Australia. Journal of Affective Disorders 183, 142-148.

Ueda, M., Y. Sawada, Y., and T. Matsubayashi. 2015. "The effectiveness of installing physical barriers for preventing railway suicides and accidents: Evidence from Japan" Journal of Affective Disorders 178, 1-4.

Uittenbogaard, A., and V. Ceccato. 2015. "Temporal and spatial patterns of suicides in Stockholm's subway stations" Accident Analysis \& Prevention 81, 96-10.

Van der Feltz-Cornelis, C.M., M. Sarchiapone, V. Postuvan, D. Volker, S. Roskar, A.T. Grum, V. Carli, D. McDaid, R. O'Connor, M. Maxwell, A. Ibelshäuser, C. Van Audenhove, G. Scheerder, M. Sisask, R. Gusmão, and U. Hegerl. 2011. "Best practice Elements of multilevel suicides prevention strategies" Crisis 32(6), 319-333.

van Houwelingen, C., and A. Kerkhof. 2008. "Mental healthcare status and psychiatric diagnoses of train suicides" Journal of Affective Disorders 107: 281-284.

van Houwelingen, C., 2011. Studies into train suicide: the contribution of psychopathology, railway parameters and environmental factors. PhD Thesis, Vrije Universiteit, The Netherlands.

Volinn, E. 1999. "Do workplace interventions prevent low back disorders? If so, why?: a methodologic commentary" Ergonomics 42(1), 258-272.

Waggoner, J., J.D. Carline, and S.J. Durning 2016. "Is there a consensus on consensus methodology? Descriptions and recommendations for future consensus research" Academic Medicine 91 (5), 663 668.

Wisniewski, J., and G.M. Havârneanu. 2016. "RESTRAIL Toolbox-An Innovative Solution for Safe, Secure and Resilient Railway Operation" Transportation Research Procedia 14, 1829-1838.

Yang, A.C., S.J. Tsai, C.H.Yang, B.C. Shia, J.L. Fuh, S.J. Wang, C.K. Peng, and N.E. Huang. 2013. "Suicide and media reporting: a longitudinal and spatial analysis" Social Psychiatry and Psychiatric Epidemiology 48(3), 427-35. 


\section{List of Figures}

Figure 1 Features of the evaluation method

\section{List of Tables}

Table 1 Criteria for the evaluation

Table 2 Summary of the evaluation results

Table 3 Scores given to different qualitative evaluation criteria

Table 4 Recommended and promising measures for the prevention of railway suicides and trespassing, including comparison of evidence from the literature

Table 5 Examples of commentary on the implementation and likely success of different measures

Table 6 Selection of different types of preventative measures for suicide and trespass from applying the evaluation methodology

Table 7 Classification of selected and non-selected preventative measures by different mechanisms of effect (extended from Rådbo et al. 2008) 
Clarify the tasks or questions to be addressed (S3.1)

\begin{tabular}{|l|}
\hline $\begin{array}{l}\text { Core group* } \\
\text { - Background (3 from industry, } 4 \text { University, } 3 \text { research org.) } \\
\text { - Background (Sweden, the Netherlands, France, Finland, UK, } \\
\text { Germany) }\end{array}$ \\
\begin{tabular}{|l|}
\hline Wider group** \\
- Roles (core group, plus 10 from industry, 2 research org. \\
- Countries (France, Sweden, Belgium, the Netherlands, \\
Finland, UK, Germany, Spain, Switzerland)
\end{tabular} \\
\hline
\end{tabular}

\section{Search for, and classification of, known measures (S3.3.1) *}

Prepare appropriate scientific evidence $\quad$ Identification and use of evaluation criteria (S3.3.2) * (s3.3)

\begin{tabular}{|l|l|}
\hline Collate evidence on forms (S3.3.2)* \\
\hline
\end{tabular}

Review and achieve consensus on evidence and ratings for different measures (S3.4)

\section{Create reference material for use by} larger expert group * (ii) Identify best measures

I

Consultation and agreement on qualitative evidence and quantitative estimates and ratings (Table 2,3) **

\section{Analysing, synthesising and}

interpreting data and judgements on

preventative measures (S3.5)

\begin{tabular}{|l|}
\hline $\begin{array}{l}\text { Identify recommended and promising } \\
\text { measures (Table 4)*** }\end{array}$ \\
\hline $\begin{array}{l}\text { Interpretation of findings using literature } \\
(\text { Table } 4,6)^{*}\end{array}$ \\
\hline $\begin{array}{l}\text { Additional classification by type and } \\
\text { underlying mechanism of effect (Table 7) * }\end{array}$ \\
\hline
\end{tabular}

Figure 1 Features of the evaluation method 


\begin{tabular}{|c|c|c|}
\hline \multicolumn{2}{|c|}{ Criteria } & \multirow{4}{*}{$\begin{array}{l}\text { Characteristics } \\
\text { Description / } \\
\text { qualitative detail on } \\
\text { the safety measure } \\
\text { and context }\end{array}$} \\
\hline$* 1$. & Description of relevant features of the measure. & \\
\hline$* 2$ & $\begin{array}{l}\text { Definition of target incidents - whether the measure is intended to reduce } \\
\text { certain types of incidents or focus on a specific group of people (such as } \\
\text { children) }\end{array}$ & \\
\hline$* 3$ & $\begin{array}{l}\text { Size of the problem - a quantitative estimate of the frequency of target } \\
\text { incidents (e.g. trespassing accidents in the target group per year). }\end{array}$ & \\
\hline$* 14$ & $\begin{array}{l}\text { Effect on incidents - the expected effect of the measure on target incidents, } \\
\text { based on evidence from field studies or estimates by experts. }\end{array}$ & $\begin{array}{l}\text { Assessment of effect } \\
\text { of the safety measure }\end{array}$ \\
\hline$* 5$ & $\begin{array}{l}\text { Durability of effects - whether the effects of the measure are likely to be } \\
\text { permanent or erode with time. }\end{array}$ & $\begin{array}{l}\text { Additional rail } \\
\text { related and other }\end{array}$ \\
\hline$* 6$ & $\begin{array}{l}\text { Costs and benefits - approximate estimates of the costs and benefits, if } \\
\text { available, or determination of the likely cost - benefit ratio. }\end{array}$ & $\begin{array}{l}\text { criteria that influence } \\
\text { the implementation }\end{array}$ \\
\hline 7. & $\begin{array}{l}\text { Integration with other policy measures - whether the measure will work well } \\
\text { alongside other preventative measures or interventions. }\end{array}$ & $\begin{array}{l}\text { and effectiveness of } \\
\text { the safety measure }\end{array}$ \\
\hline 8. & $\begin{array}{l}\text { Impact on railway operations - whether there are likely to be positive or } \\
\text { negative effects on the train service. }\end{array}$ & \\
\hline 9. & $\begin{array}{l}\text { Impact on people and jobs in the railway industry - whether implementing the } \\
\text { measure may increase or decrease risks to health and job opportunities within } \\
\text { the railway industry. }\end{array}$ & \\
\hline 10. & $\begin{array}{l}\text { Technological issues - whether there is need for changes in the existing } \\
\text { technology and infrastructure, also considering the level of readiness of } \\
\text { technology for effective implementation of the new safety measure. }\end{array}$ & \\
\hline 11. & $\begin{array}{l}\text { Environmental issues - whether there are likely to be impacts on the } \\
\text { environment from introducing the measure (e.g. pollution, impacts on } \\
\text { scenery and wildlife). }\end{array}$ & \\
\hline$* 12$. & $\begin{array}{l}\text { Acceptance - whether the measure will be accepted by the public and relevant } \\
\text { stakeholders (e.g. policy makers, industry). }\end{array}$ & \\
\hline$* 13$ & $\begin{array}{l}\text { Transferability - how the measure can be transferred and applied in different } \\
\text { railway contexts. }\end{array}$ & \\
\hline 14. & $\begin{array}{l}\text { Additional information - any relevant information that is not dealt with in the } \\
\text { criteria listed above. This will include assessment of the strengths, } \\
\text { weaknesses, opportunities and threats associated with the measure. }\end{array}$ & \\
\hline
\end{tabular}

*Based on the original criteria used by Elvik (SUPREME, 2007, Elvik, 2012)

${ }^{1}$ Expected effects and Actual impacts were used in the earlier work by Elvik

Table 1 Criteria for the evaluation 
2 Light to increase visibility at hotspots e.g. Lighting at identified hotspots such as crossings, tunnels and bridges

3 Temporary speed reduction or traffic shut-down when a risk is detected e.g. stopping or slowing down trains when there is a report of someone on the line

4 Landscaping e.g. Removal of vegetation to increase visibility

Surveillance technologies to identify and prevent incidents e.g. using CCTV cameras, fake CCTV camera boxes or infrared cameras

6 Lighting devices to influence behaviour e.g. Dispelling light source, lighting linked to movement sensor

7 Detection and surveillance systems e.g. Intelligent CCTV combined with sound warnings

8 Patrols and enforcement e.g. Security patrols, security patrols able to fine

9 Surveillance technologies to detect behaviour e.g. RADAR / Glass fibre sensing devices

10 CCTV cameras/motion detectors, linked to (train)traffic stop warnings e.g. use of CCTV technologies, but with the addition of better links to traffic control systems

11 Information sharing at regional level e.g. Surveillance based on local intelligence from the police or health authorities

12 Campaigns to raise awareness e.g. Targeted campaigns for the general public or towards vulnerable groups for suicide or trespass

13 Education in and outside schools e.g. as part of lessons in the curriculum or part of community activities

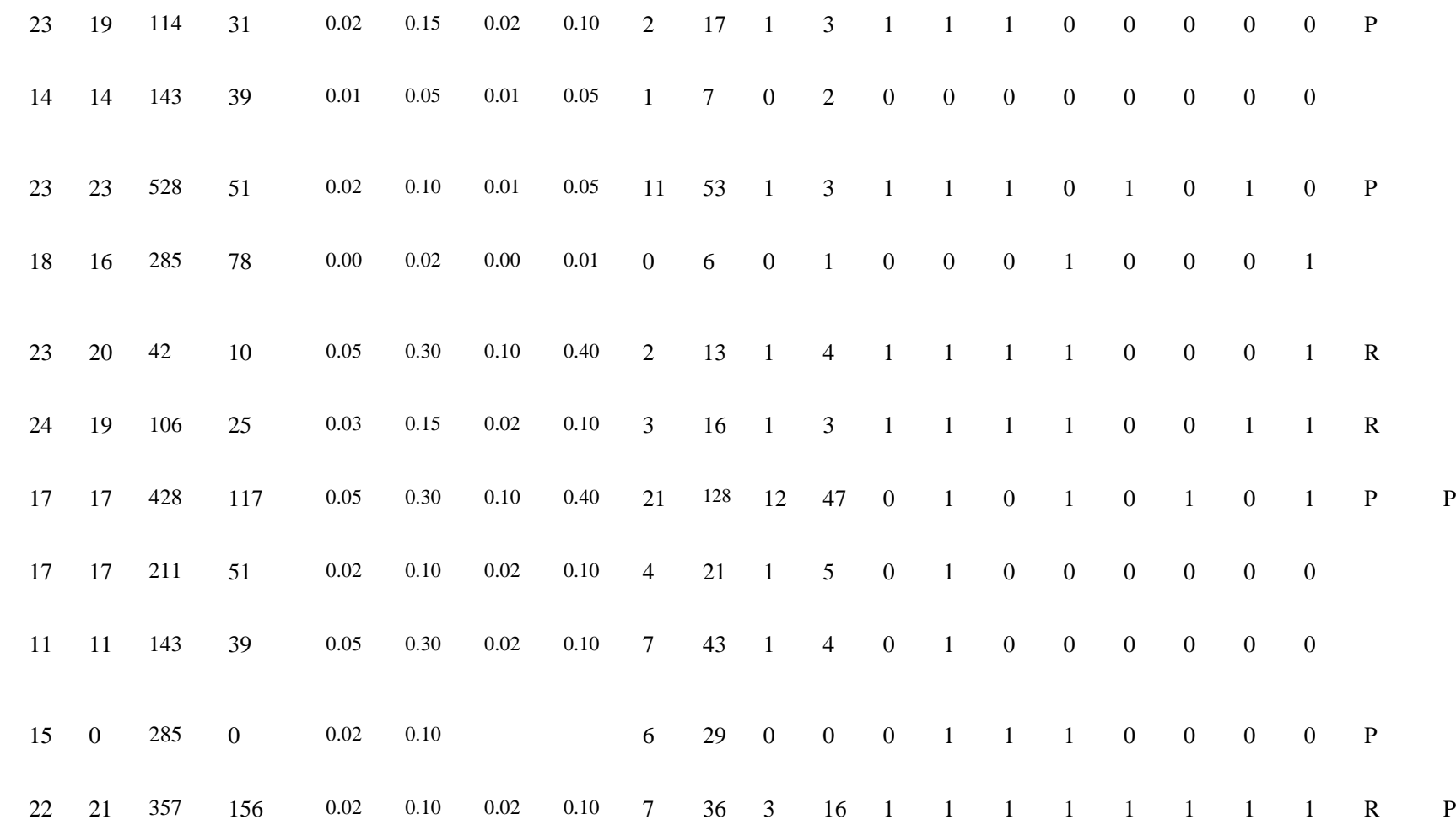




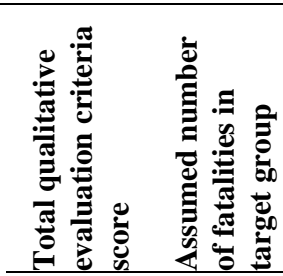

Effect on targeted

Estimated

Categorisation criteria ("1" indicates

\section{fatalities}

reduction in the

passing of threshold value)

$\%$ reduction - presented as annual number of

Suicides

fatalities

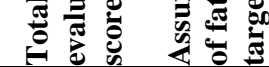

Suicides

Trespass

Scores for Trespass

Mass media campaigns e.g. National campaigns, campaigns

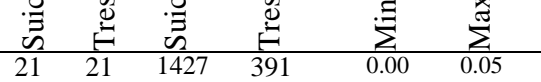
about safety

15 Media Guidelines e.g. Media guidelines to avoid copycat $\begin{array}{llll}22 & 21 & 714 & 196\end{array}$ effects, announcements made to passengers after an incident, removal of death memorials

16 Staff Support (staff at risk of suicide) e g to support staff who might be at greater risk following a suicide event

17 Additional technologies for train drivers e.g. spotlights, in-cab CCTV, additional technologies that could be available to drivers in their cab

18 Emergency button at unstaffed stations e.g. linked to a helpline or security staff

19 Training of staff at stations - Gatekeeper training e.g. training of frontline staff who may be able to intervene to prevent an incident

20 Training of staff at stations - General Awareness Rising e.g. raising awareness of general risks of access to the railway, not necessarily suicide

21 Training of drivers / instructions to drivers e.g. about responding to incidents or risky behaviours

22 Outreach support by trained staff on call e.g. includes signs and helplines to get support from trained staff

23 Design of stations and other locations to influence the movements of people e.g. various physical interventions such as floor markings on areas of the platform, design of access gates, removal of places for hiding

24 Design of stations and other locations e.g. various environmental influences such as colours, lighting, music and other devices

25 Fences at stations e.g. Mid-platform fencing, fencing platform ends, anti-trespass grids

26 Fences outside stations e.g. Fencing at hotspots, nets at

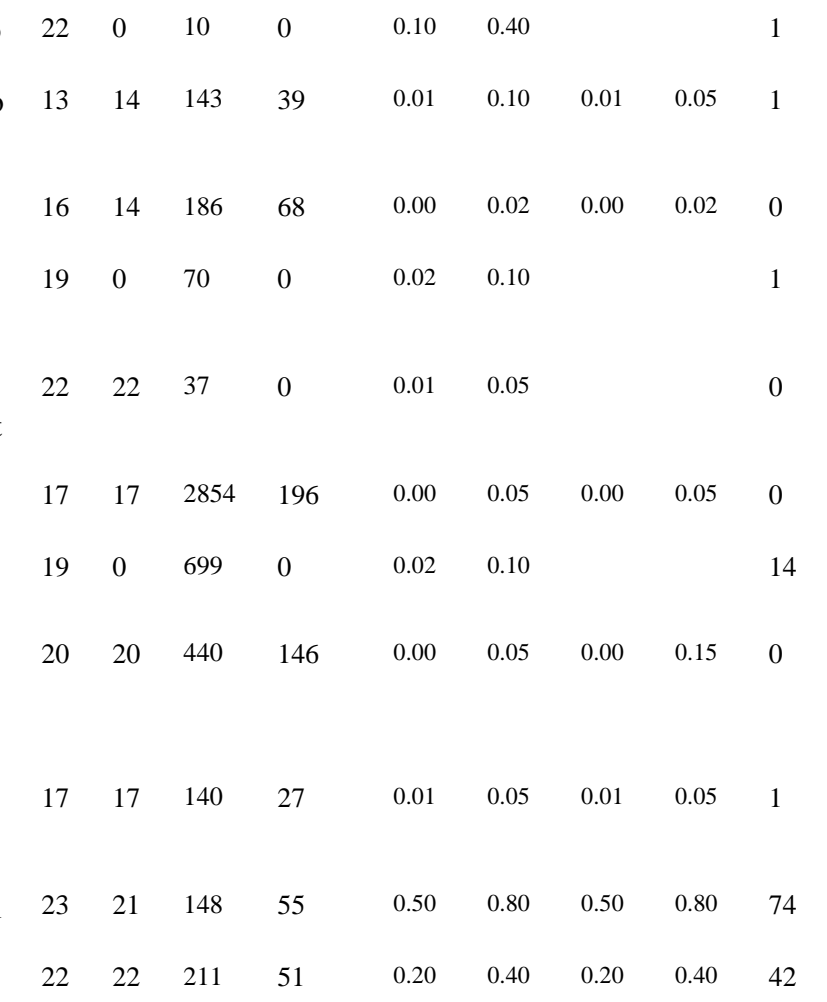




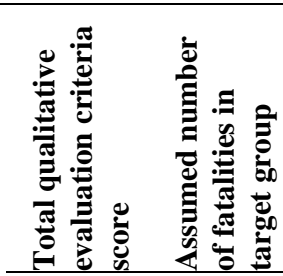

Effect on targeted

Estimated

Categorisation criteria ("1" indicates

\section{fatalities}

reduction in the

passing of threshold value)

$\%$ reduction - presented as annual number of

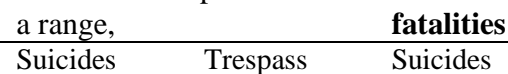
fatalities
Suicides

Trespass

Suicides Trespass Scores for Suicides

Scores for Trespass

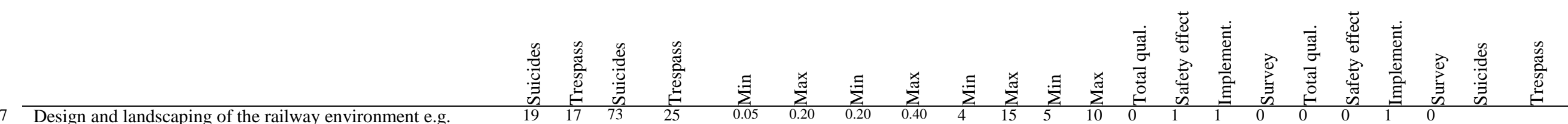

providing alternative pathways, safe crossing areas, using

natural vegetation as barriers

28 Suicide pits at stations e.g. design of the track areas to reduce the opportunity for people to make contact with the train after jumping off platforms

29 Safety and emergency information at stations e.g. Emergency information to ensure rapid intervention, information encouraging help seeking for people with suicidal intent

30 Prohibitive signs

31 Posters and warning signs

32 Airbags in front of trains e.g. airbags or nets to reduce the impact of trains in the event of a collision with a person

33 Design of trains to reduce the effects of impact e.g. removing sharp, angular protrusions that would cause greater injury

34 Transfer of cost to family members e.g. in an effort to prevent people taking the decision to take their life or take risks on the railway as a result of costs that would be borne by others

35 Collaboration between organisations e.g. Clarification of responsibilities, communication strategy, consultation with psychiatric hospitals

36 Risk assessment e.g. Identification of hotspots, planning for special circumstances

37 Learning from best practice e.g. Learning from international experience, previous national experience and research studies

38 Societal collaboration to prevent railway suicides e.g.

National prevention strategies, such as better coordination and fast response from all emergency services in the event of an incident or threat of incident

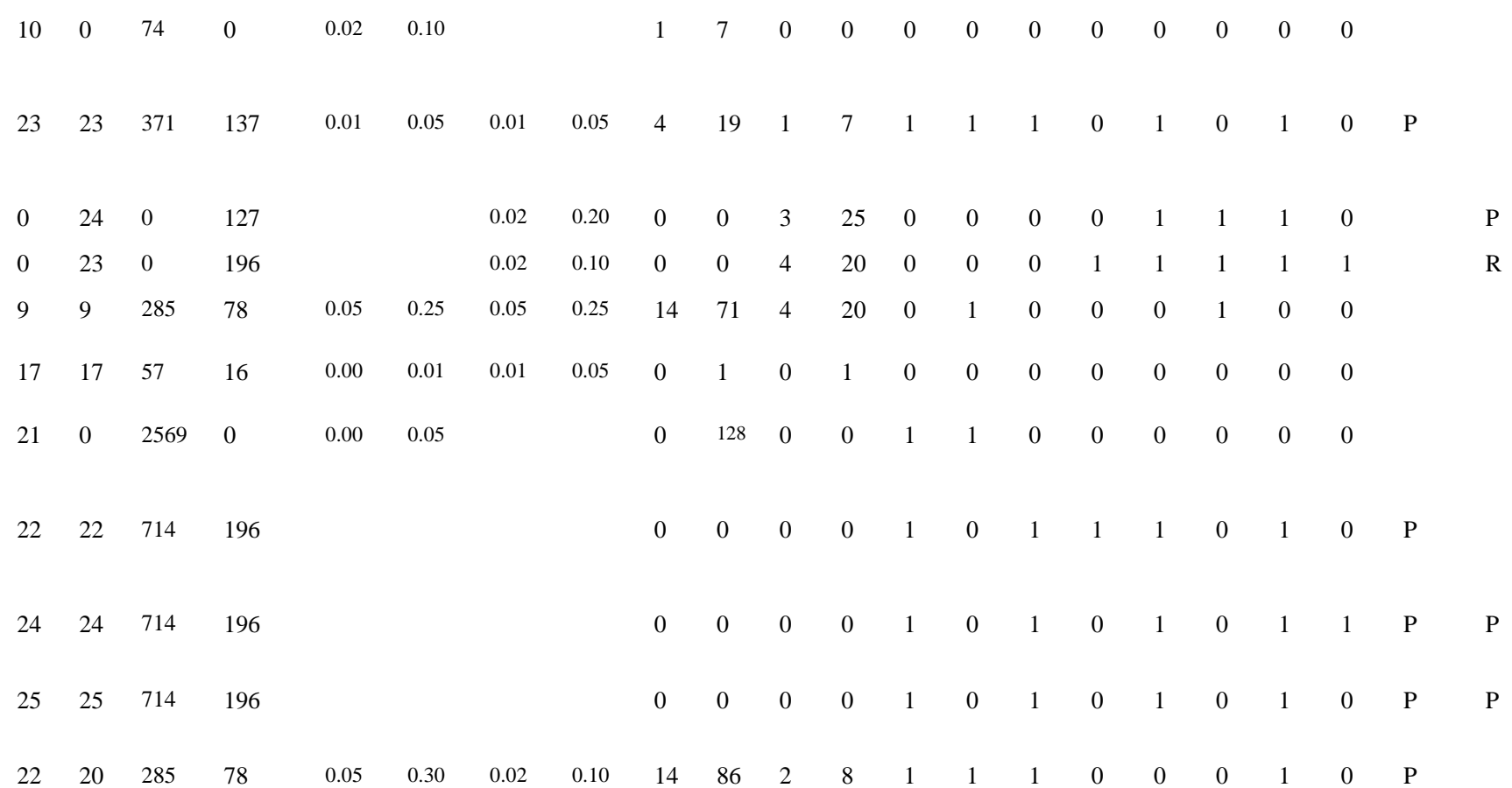

Table 2 Summary of the evaluation results 


\section{ID Types of measures}

\begin{tabular}{|c|c|c|c|c|c|c|c|c|c|c|c|c|c|c|c|c|c|c|c|}
\hline 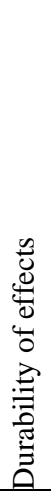 & 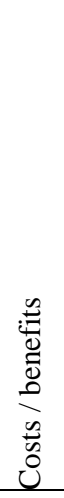 & 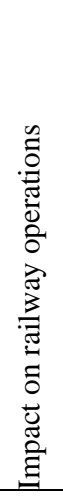 & 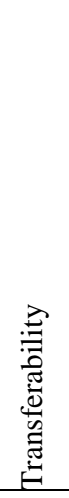 & 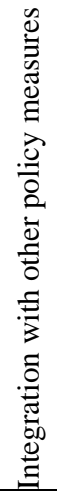 & 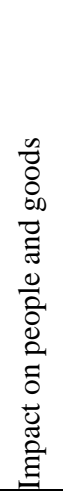 & 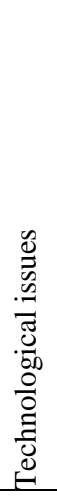 & 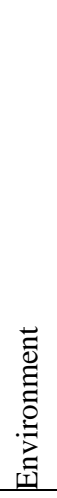 & 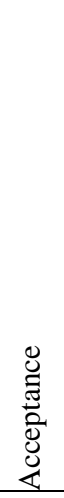 & 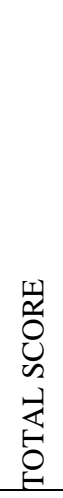 & 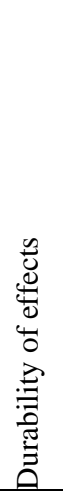 & 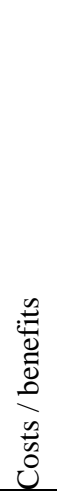 & 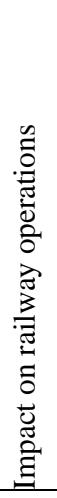 & 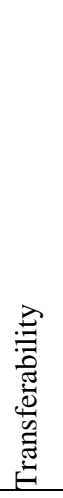 & 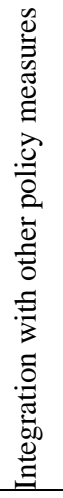 & 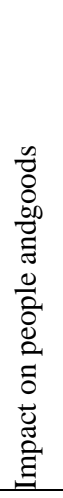 & 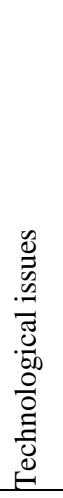 & 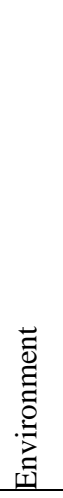 & 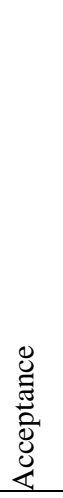 & 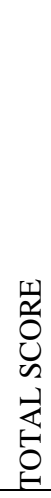 \\
\hline 2 & 2 & 2 & 2 & 1 & 1 & 1 & 1 & 1 & & 2 & 2 & 2 & 2 & 1 & 1 & 1 & 1 & 1 & \\
\hline 4 & 4 & 4 & 0 & 2 & 2 & 2 & 2 & 0 & 20 & \multicolumn{10}{|c|}{ not applicable } \\
\hline 4 & 4 & 4 & 4 & 1 & 2 & 2 & 1 & 1 & 23 & 2 & 2 & 4 & 4 & 1 & 2 & 2 & 1 & 1 & 19 \\
\hline 4 & 0 & 0 & 4 & 0 & 2 & 2 & 2 & 0 & 14 & 4 & 0 & 0 & 4 & 0 & 2 & 2 & 2 & 0 & 14 \\
\hline 4 & 4 & 4 & 4 & 1 & 2 & 2 & 1 & 1 & 23 & 4 & 4 & 4 & 4 & 1 & 2 & 2 & 1 & 1 & 23 \\
\hline 0 & 4 & 4 & 2 & 1 & 2 & 2 & 2 & 1 & 18 & 0 & 2 & 4 & 2 & 1 & 2 & 2 & 2 & 1 & 16 \\
\hline 4 & 4 & 4 & 4 & 2 & 2 & 1 & 1 & 1 & 23 & 4 & 2 & 4 & 4 & 2 & 2 & 1 & 1 & 0 & 20 \\
\hline 4 & 4 & 4 & 4 & 2 & 2 & 2 & 1 & 1 & 24 & 2 & 2 & 4 & 4 & 1 & 2 & 2 & 1 & 1 & 19 \\
\hline 0 & 0 & 4 & 4 & 2 & 2 & 1 & 2 & 2 & 17 & 0 & 0 & 4 & 4 & 2 & 2 & 1 & 2 & 2 & 17 \\
\hline 2 & 2 & 2 & 4 & 1 & 2 & 0 & 2 & 2 & 17 & 2 & 2 & 2 & 4 & 1 & 2 & 0 & 2 & 2 & 17 \\
\hline 4 & 2 & 2 & 0 & 0 & 1 & 0 & 2 & 0 & 11 & 4 & 2 & 2 & 0 & 0 & 1 & 0 & 2 & 0 & 11 \\
\hline 2 & 2 & 2 & 2 & 1 & 1 & 2 & 2 & 1 & 15 & \multicolumn{10}{|c|}{ not applicable } \\
\hline 2 & 4 & 4 & 2 & 2 & 2 & 2 & 2 & 2 & 22 & 2 & 4 & 4 & 2 & 2 & 2 & 2 & 2 & 1 & 21 \\
\hline \multicolumn{10}{|c|}{ not applicable } & 2 & 4 & 4 & 4 & 2 & 1 & 2 & 2 & 2 & 23 \\
\hline 2 & 4 & 4 & 2 & 2 & 2 & 2 & 2 & 1 & 21 & 2 & 4 & 4 & 2 & 2 & 2 & 2 & 2 & 1 & 21 \\
\hline 2 & 4 & 4 & 2 & 2 & 2 & 2 & 2 & 2 & 22 & 2 & 4 & 4 & 2 & 2 & 2 & 2 & 2 & 1 & 21 \\
\hline 2 & 4 & 4 & 4 & 2 & 1 & 2 & 2 & 1 & 22 & \multicolumn{10}{|c|}{ not applicable } \\
\hline 4 & 0 & 2 & 4 & 0 & 0 & 0 & 2 & 1 & 13 & 4 & 0 & 2 & 4 & 0 & 1 & 0 & 2 & 1 & 14 \\
\hline 4 & 2 & 0 & 2 & 2 & 1 & 2 & 2 & 1 & 16 & 4 & 0 & 0 & 2 & 2 & 1 & 2 & 2 & 1 & 14 \\
\hline 4 & 2 & 4 & 2 & 1 & 1 & 2 & 2 & 1 & 19 & \multicolumn{10}{|c|}{ not applicable } \\
\hline 4 & 4 & 4 & 2 & 2 & 1 & 2 & 2 & 1 & 22 & 4 & 4 & 4 & 2 & 2 & 1 & 2 & 2 & 1 & 22 \\
\hline
\end{tabular}




\section{ID Types of measures}

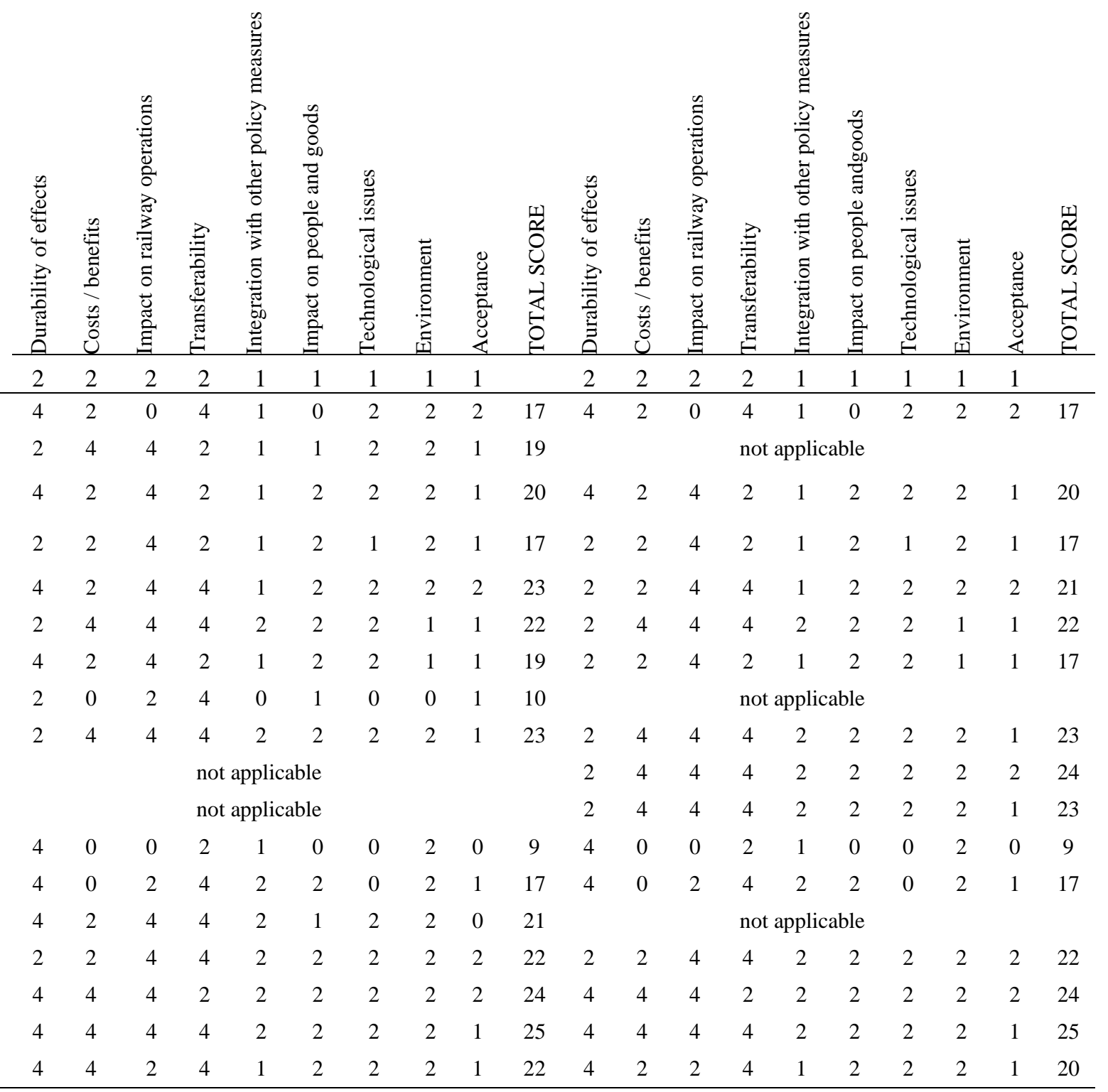

Table 3 Scores given to different qualitative evaluation criteria. 
ID Types of measures measures Including examples of specific

Classification for

prevention

$\mathbf{R}=$ Recommended

$\mathbf{P}=$ Promising

Suicide

$6 \quad$ Lighting devices to influence behaviour

e.g. Dispelling light source, lighting

linked to movement sensor

7 Detection and surveillance system e.g. Intelligent CCTV combined with sound warnings

12 Campaigns to raise awareness e.g. Targeted campaigns towards vulnerable groups

13 Education in and outside schools

25 Fences at stations e.g. Mid-platform fencing, fencing platform ends, anti-trespass grids

26 Fences outside stations

e.g. Fencing at hotspots, nets at bridges

31 Posters and warning signs

R

Commentary on the mechanism underlying the effect of the safety measure and strength of evidence

++ strong, + good, - absence of evidence, plus a summary of evidence in the literature

Environmental design to influence attractiveness of the railway for suicide or persuade people to leave a place of

\section{danger}

+ Dispelling light sources have been evaluated in Japan. An initial study (Matsubayashi et al. 2013) reported that blue lights reduced railway suicide by $84 \%$ at station platforms, but a follow-up study by Ichikawa et al. (2014), published after the expert workshop, criticises this result and argues that the effect is severely overestimated.

\section{Surveillance for early warning or persuade people to leave a place of danger}

+ DaSilva et al. (2006) have shown the effectiveness of intelligent CCTV combined with sound warnings on a railway bridge in the USA, where the trespass rate dropped by $60 \%$ from the first to the second year and by $17 \%$ (compared to the first one) in the third year. Too et al. (2015) found increased numbers of video surveillance systems at railway stations was associated with a modest reduction in railway suicide risk.

Education / campaigns to influence attractiveness of the railway for suicide

- Mentioned in the following literature, but not studied in any depth - (Bureau of Transport and Regional Economics 2002; CARE 2006; DaSilva and Carroll 2011; Horton 2009; Lobb et al. 2001; Lobb et al. 2003; Mishara 2007; Mohanty et al. 2007; Pelletier 1997; RSSB 2002; RSSB 2003; RSSB 2012).

Education / campaigns to influence attractiveness of the railway for trespass

+ Education at schools dedicated to risk and safety helped reduce trespass behaviour when combined with communication and enforcement (Lobb et al. 2003) or fencing and signage (Lobb et al. 2001).

\section{Physical measures to influence access to the tracks}

++ Strong evidence from multiple studies in various countries, with access restriction through different types of fencing and barriers (e.g. sliding doors at platforms, nets at bridges, or fencing at stations and open line hotspots). Cox et al. (2013) reported strong evidence of the effect of reducing means of access to suicide, without substitution effects. Pirkis et al. (2015) reported how restricting access to means of suicide was associated with a reduction in risk of suicide. Physical barriers found to reduce fatalities at suicide hotspots by $59 \%$ (Law et al 2009; Law and Yip 2011), 76\% (Ueda et al. 2015 for half-height platform screen doors) and 100\% (Beautrais at al. 2009 - nets at bridges) and reduce trespassing behaviour between 23\% (Lobb et al. 2001) and 95\% (Silla and Luoma 2011) at trespass priority locations. Positive effects of fencing are also reported by Reisch and Michel (2005), Hepp et al. (2012), and Pirkis et al. (2015) against suicide by jumping.

\section{Education / warnings to influence attractiveness of the railway for suicide or persuade people to leave a place of} danger

+ Lobb et al. (2001) evaluated the effect of warning signs and posters in combination with fencing and education and found that it significantly decreased trespass at a railway station in New Zealand. 
ID Types of measures Including examples of specific measures
Classification for

prevention

$\mathbf{R}=$ Recommended

$\mathbf{P}=$ Promising

Suicide
Commentary on the mechanism underlying the effect of the safety measure and strength of evidence

\section{in the literature}

++ strong, + good, - absence of evidence, plus a summary of evidence in the literature
2 Light to increase visibility at hotspots

e.g. Lighting at identified hotspots

$4 \quad$ Landscaping

e.g. Removal of vegetation to

increase visibility

8 Patrols and enforcement

e.g. Security patrols, security patrols able to fine

11 Information sharing at regional level e.g. Surveillance based on local

intelligence

14 Mass media campaigns

e.g. National campaigns, campaigns about safety

15 Media Guidelines

e.g. Media guidelines to avoid copy cat effects, announcements made to passengers after an incident, removal of death memorials Trespass

Environmental design to influence attractiveness of the railway for suicide, enable early warning or persuade people to leave a place of danger

- Mentioned in the following literature, but not studied in any depth - (Erazo et al. 2005; Offler et al. 2009; Savage 2007; Mishara 2007; Thompson et al. 2012; van Houwelingen 2011)

Environmental design to influence attractiveness of the railway for suicide and enable early warning

- Mentioned in the following literature, but not studied in any depth - (Andriessen and Krysinska 2011; Debbaut et al. 2013; Horton 2009).

Surveillance to influence the attractiveness of the railway for suicide and to enable early warning

+ Security patrols against suicide are supported by Niederkrotenthaler et al. (2012) who have shown that the presence of a surveillance unit at stations is associated with a decrease of suicidal behaviours. The study by Lobb et al. (2003) also indicates that combining punishment with intermittent reinforcement of desired behaviour (i.e. rewards) significantly reduced trespass behaviour in male pupils, thus supporting recommendations for security patrols who are able to fine.

\section{Surveillance to enable early warning}

- No references in the literature.

Education / warnings to influence attractiveness of the railway for suicide

+ Mentioned in the following literature, but not studied in any depth - (Bureau of Transport and Regional Economics 2002; CARE 2006; DaSilva and Carroll 2011; Horton 2009; Lobb et al. 2001; Lobb et al. 2003; Mishara 2007; Mohanty et al. 2007; Pelletier 1997; RSSB 2002; RSSB 2003; RSSB 2012).

\section{Education / warnings to influence attractiveness of the railway for suicide}

++ Evaluation studies in different countries have reported significant increase in railway suicide following media reports of suicide incidents (Kunrath et al. 2011), moderately strong impact of media reporting (Too et al. 2014) strong copy cat effect following celebrity suicide (Hegerl et al. 2013; Koburger et al. 2015; Ladwig et al. 2012), imitation of suicide means if reported in the media (Yang et al. 2013), and contagion, especially in the groups whose age and sex were closest to those within the media report (Schmidtke and Häfner 1988). In addition, implementation of media guidelines in Vienna underground resulted in a significant decrease of suicide cases (Etzersdorfer and Sonneck 1998) and suicidal behaviours (Niederkrotenthaler and Sonneck 2007) providing strong support for effectiveness. 
ID Types of measures Including examples of specific measures
Classification for

prevention

$\mathbf{R}=$ Recommended

P=Promising

Suicide
Commentary on the mechanism underlying the effect of the safety measure and strength of evidence

\section{in the literature}

++ strong, + good, - absence of evidence, plus a summary of evidence in the literature
29 Safety and emergency information at stations

e.g. Emergency information to

ensure rapid intervention,

information encouraging help

seeking for people with suicidal intent

30 Prohibitive signs

35 Collaboration between organisations e.g. Clarification of responsibilities, communication strategy,

consultation with psychiatric hospitals

36 Risk assessment

e.g. Identification of hotspots,

planning for special circumstances

37 Learning from best practice e.g. Learning from international experience, previous national experience and research studies

38 Societal collaboration to prevent railway suicides

e.g. National prevention strategies Trespass

Education / warnings to influence attractiveness of the railway for suicide, to enable early warning or persuade people to leave a place of danger

- Mentioned in the following literature, but not studied in any depth - (Andriessen and Krysinska 2011; du Roscoät and Beck 2013; Holdaway et al. 2012; Kerkhof 2003; Ladwig et al. 2009; Mishara 2007; Routley et al. 2004). Recently, Pirkis et al. (2015) reported how encouraging help-seeking was associated with a reduction in risk of suicide.

$\mathrm{P} \quad$ Information to influence access to the tracks and persuade people to leave a place of danger

+ Silla and Luoma (2011) evaluated the effectiveness of prohibitive signs at a trespass hotspot in Finland and found that trespass behaviour dropped by $30.7 \%$.

Organisational / inter-organisational approaches

- Mentioned in the following literature, but not studied in any depth - (Baumert et al 2011; Bureau of Transport and Regional Economics 2002; CARE 2006; DaSilva et al. 2006; George 2007; Lobb et al. 2001; Patterson 2004; RSSB 2005; RSSB 2011; Thompson et al. 2012).

$\mathrm{P}$

$\mathrm{P}$

Organisational / inter-organisational approaches

- Mentioned in the following literature, but not studied in any depth - for risk assessemnt (Bhui et al. 2013; Debbaut et al. 2013; Erazo et al. 2004; Lukaschek et al. 2014; Niederkrotenthaler et al. 2012; Routley et al. 2004; van Houwelingen and Kerkhof 2008), station audits (RSSB 2013), and follow-up processes (RSSB 2012).

\section{Organisational / inter-organisational approaches}

- No references in the literature.

\section{Organisational / inter-organisational approaches}

+ Baumert et al. (2011) have shown that the German national railway suicide prevention strategy had positive results, reducing the number of suicides by almost $14 \%$

Table 4 Recommended and promising measures for the prevention of railway suicides and trespassing, including comparison evidence from the literature. 


\begin{tabular}{ll}
\hline Type of comment & Examples \\
\hline $\begin{array}{l}\text { Practicalities or } \\
\text { limitations of } \\
\text { measures }\end{array}$ & $\begin{array}{l}\text { It was explained how some measures might work in practice e.g. outreach workers at } \\
\text { a station. }\end{array}$ \\
$\begin{array}{l}\text { The durability or longevity of measures was mentioned e.g. the need for repeated } \\
\text { application of some measures, such as education in schools as children grow up and } \\
\text { new cohorts come along. }\end{array}$ \\
$\begin{array}{l}\text { Potential negative } \\
\text { impacts of measures }\end{array}$ & $\begin{array}{l}\text { There may be some unexpected effects in some geographical locations e.g. removal } \\
\text { of vegetation could impact on soil erosion in countries such as Turkey, or impacts on } \\
\text { delay costs of stopping trains after receiving warnings of trespass. }\end{array}$ \\
& $\begin{array}{l}\text { There is the potential for distraction if drivers need to monitor CCTV displays in the } \\
\text { cab e.g. on the line ahead. }\end{array}$ \\
$\begin{array}{l}\text { Identification of new } \\
\text { measures }\end{array}$ & $\begin{array}{l}\text { Examples included glass fibre sensor cables to detect trespass along the length of the } \\
\text { railway line, including how people would need to react to the triggering of the sensor } \\
\text { and impacts on delay costs if trains were required to slow down. } \\
\text { There can also be difficulties in applying media guidelines as new media emerge. }\end{array}$ \\
$\begin{array}{l}\text { Problems applying } \\
\text { the methodology }\end{array}$ & $\begin{array}{l}\text { There can be difficulties providing ratings for some measures, such as where their } \\
\text { definition is quite wide ranging (e.g. the design of stations and other locations). }\end{array}$ \\
\hline
\end{tabular}

Table 5 Examples of commentary on the implementation and likely success of different measures 


\begin{tabular}{|c|c|c|c|}
\hline $\begin{array}{l}\text { Groupings of different } \\
\text { types of preventative } \\
\text { measures }\end{array}$ & $\begin{array}{l}\text { Recommended or } \\
\text { promising } \\
\text { measures for } \\
\text { prevention } \\
\text { Count of categories of } \\
\text { types of measures } \\
\text { [ID numbers - see } \\
\text { table } 2 \text { for details] }\end{array}$ & $\begin{array}{l}\text { Questionable } \\
\text { measures in } \\
\text { terms of } \\
\text { prevention } \\
\text { Count of categories of } \\
\text { types of measures } \\
\text { [ID numbers - see } \\
\text { table } 2 \text { for details] }\end{array}$ & $\begin{array}{l}\text { Comparison with findings from } \\
\text { Havârneanu et al, } 2015 \\
\text { - showing the order based on citation } \\
\text { statistics and the description of the } \\
\text { measure used in the paper }\end{array}$ \\
\hline $\begin{array}{l}\text { Awareness / education } \\
\text { (including various types of } \\
\text { campaigns, education in } \\
\text { schools, media guidelines, } \\
\text { signs and information at } \\
\text { stations) }\end{array}$ & $\begin{array}{l}6 \\
{[12,13,14,15,29,} \\
31]\end{array}$ & & $\begin{array}{l}\text { 5. Education and enforcement at } \\
\text { individual level } \\
\text { 7. Public safety communication } \\
\text { 8. Signage } \\
\text { 17. Appropriate reporting or } \\
\quad \text { broadcast of critical incidents }\end{array}$ \\
\hline $\begin{array}{l}\text { Organisational initiatives } \\
\text { (including collaboration } \\
\text { between organisations, risk } \\
\text { assessment and learning } \\
\text { from best practice) }\end{array}$ & $\begin{array}{l}4 \\
{[35,36,37,38]}\end{array}$ & $\begin{array}{l}1 \\
{[16]}\end{array}$ & $\begin{array}{l}\text { 2. Collaboration between institutions } \\
\text { 11. Risk assessment } \\
\text { 12. Learning from previous research } \\
\text { and best practice }\end{array}$ \\
\hline $\begin{array}{l}\text { Physical and other } \\
\text { measures to restrict access } \\
\text { (including fences and } \\
\text { prohibition signs) }\end{array}$ & $\begin{array}{l}3 \\
{[25,26,30]}\end{array}$ & & 1. Fencing and other physical barriers \\
\hline $\begin{array}{l}\text { Environmental design } \\
\text { (including layouts or } \\
\text { stations, aesthetics, } \\
\text { landscaping to reduce } \\
\text { access, pits beneath tracks) }\end{array}$ & $\begin{array}{l}3 \\
{[2,4,6]}\end{array}$ & $\begin{array}{l}4 \\
{[23,24,27,28]}\end{array}$ & $\begin{array}{l}\text { 3. Environmental design } \\
\text { 13. Lighting systems to influence } \\
\text { behaviour } \\
\text { 15. Design aesthetics to influence } \\
\text { behaviour }\end{array}$ \\
\hline $\begin{array}{l}\text { Surveillance } \\
\text { (including sensors, CCTV, } \\
\text { training of staff / outreach } \\
\text { workers, public operated } \\
\text { emergency buttons) }\end{array}$ & $\begin{array}{l}3 \\
{[7,8,11]}\end{array}$ & $\begin{array}{l}7 \\
{[5,9,10,18,19} \\
20,22]\end{array}$ & $\begin{array}{l}\text { 4. Monitoring and detection systems } \\
\text { 6. Enforcement, punishment and } \\
\text { controls } \\
\text { 10. Staff training } \\
\text { 18. Emergency information and } \\
\text { outreach support at hotspots }\end{array}$ \\
\hline $\begin{array}{l}\text { Dissuading use of the } \\
\text { railway for suicide } \\
\text { (including charging family } \\
\text { costs and promoting other } \\
\text { alternatives for suicide) }\end{array}$ & & $\begin{array}{l}2 \\
{[1,34]}\end{array}$ & $\begin{array}{l}\text { 19. Decrease attractiveness of the } \\
\text { railways as a lethal method }\end{array}$ \\
\hline $\begin{array}{l}\text { Train driver support } \\
\text { (including technological } \\
\text { and training solutions) }\end{array}$ & & $\begin{array}{l}2 \\
{[17,21]}\end{array}$ & $\begin{array}{l}\text { 14. Additional technologies for train } \\
\text { drivers }\end{array}$ \\
\hline $\begin{array}{l}\text { Train design } \\
\text { (including airbags and } \\
\text { redesign of the fronts of } \\
\text { trains) }\end{array}$ & & $\begin{array}{l}2 \\
{[32,33]}\end{array}$ & $\begin{array}{l}\text { 9. Technical design to reduce the } \\
\text { effects of impact }\end{array}$ \\
\hline $\begin{array}{l}\text { Operational traffic } \\
\text { management } \\
\text { (e.g. stopping trains when a } \\
\text { risk is identified) }\end{array}$ & & $\begin{array}{l}1 \\
{[3]}\end{array}$ & 16. Operational train management \\
\hline
\end{tabular}

Table 6 Selection of different types of preventative measures for suicide and trespass from applying the evaluation methodology 


\begin{tabular}{|c|c|c|}
\hline $\begin{array}{l}\text { Mechanisms of effect of the } \\
\text { preventative measures }\end{array}$ & $\begin{array}{l}\text { Recommended or promising } \\
\text { measures for prevention } \\
\text { Count } \\
{[I D \text { numbers - see table } 2 \text { for }} \\
\text { details] }\end{array}$ & $\begin{array}{l}\text { Questionable measures in terms } \\
\text { of prevention } \\
\text { Count } \\
{[\text { ID numbers - see table } 2 \text { for }} \\
\text { details] }\end{array}$ \\
\hline $\begin{array}{l}\text { Influencing the attractiveness or } \\
\text { availability of the railway for } \\
\text { suicide }\end{array}$ & $\begin{array}{l}10 \\
{[2,4,6,8,12,13,14,15,21,31]}\end{array}$ & $\begin{array}{l}6 \\
{[1,3,5,23,24,34]}\end{array}$ \\
\hline Influencing access to the railway & $\begin{array}{l}3 \\
{[26,27,30]}\end{array}$ & $\begin{array}{l}2 \\
{[23,27]}\end{array}$ \\
\hline Early warning of risk of incident & $\begin{array}{l}6 \\
{[2,4,7,8,11,29]}\end{array}$ & $\begin{array}{l}6 \\
{[5,9,10,19,20,22]}\end{array}$ \\
\hline $\begin{array}{l}\text { Persuading people to leave a place } \\
\text { of risk }\end{array}$ & $\begin{array}{l}6 \\
{[2,6,7,29,30,31]}\end{array}$ & $\begin{array}{l}3 \\
{[17,18,19]}\end{array}$ \\
\hline $\begin{array}{l}\text { Mitigation of consequences of } \\
\text { collision }\end{array}$ & 0 & $\begin{array}{l}5 \\
{[17,21,28,32,33]}\end{array}$ \\
\hline $\begin{array}{l}\text { Organisational / inter- } \\
\text { organisational }\end{array}$ & $\begin{array}{l}4 \\
{[35,36,37,38]}\end{array}$ & $\begin{array}{l}1 \\
{[16]}\end{array}$ \\
\hline
\end{tabular}

Table 7 Classification of selected and non-selected preventative measures by different mechanisms of effect (Extended from Rådbo et al, 2008) 
